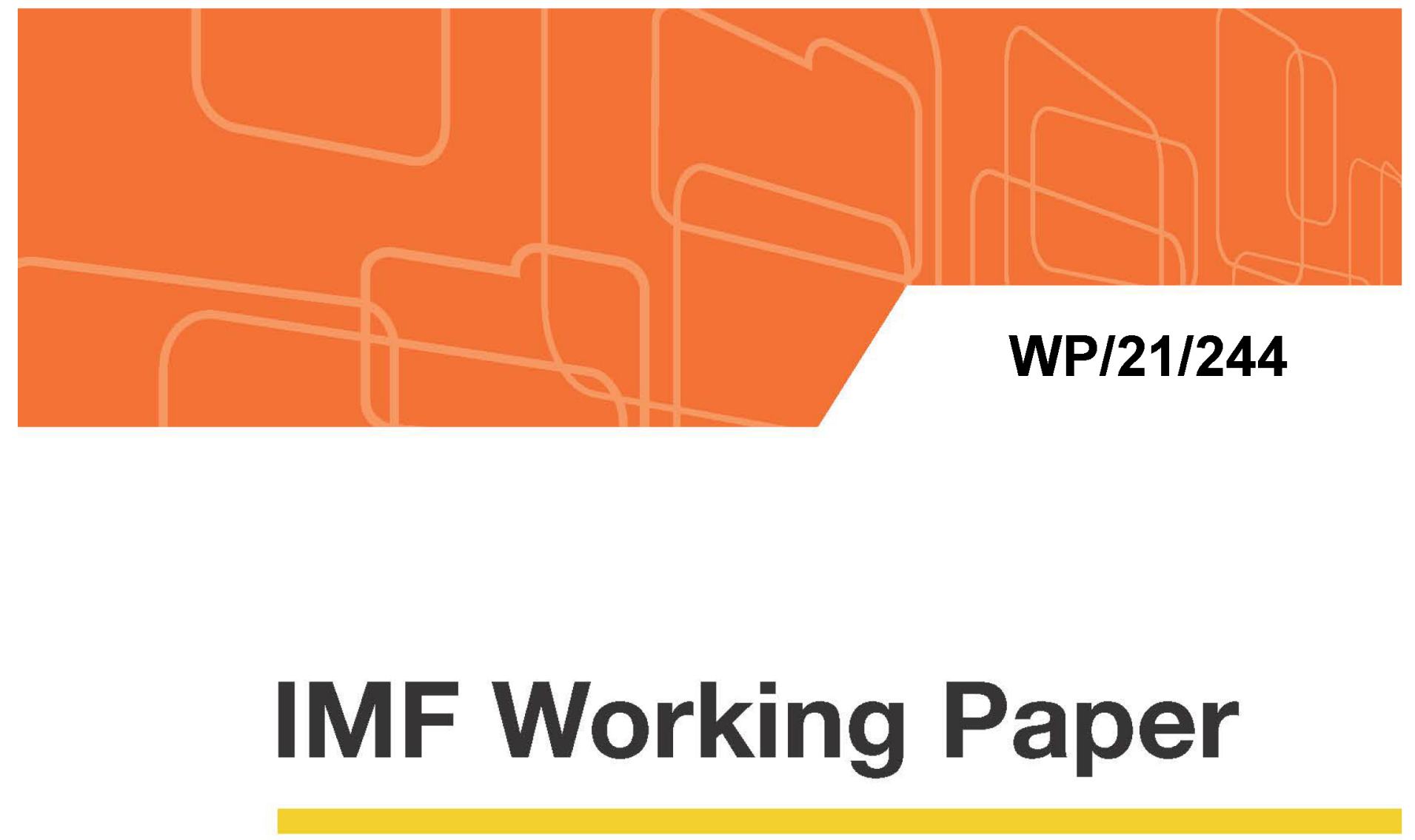

\title{
Social Spending in Mexico: Needs, Priorities and Reforms
}

by Swarnali Ahmed Hannan, Juan Pablo Cuesta Aguirre and David Bartolini

IMF Working Papers describe research in progress by the author(s) and are published to elicit comments and to encourage debate. The views expressed in IMF Working Papers are those of the author(s) and do not necessarily represent the views of the IMF, its Executive Board, or IMF management. 


\title{
IMF Working Paper
}

Western Hemisphere Department

\author{
Social Spending in Mexico: Needs, Priorities and Reforms \\ Prepared by Swarnali Ahmed Hannan, Juan Pablo Cuesta Aguirre and David Bartolini \\ Authorized for distribution by Rishi Goyal
}

October 2021

\section{IMF Working Papers describe research in progress by the author(s) and are published to elicit comments and to encourage debate. The views expressed in IMF Working Papers are those of the author(s) and do not necessarily represent the views of the IMF, its Executive Board, or IMF management.}

\begin{abstract}
Poverty in Mexico was high before the COVID-19 pandemic and has been exacerbated by the pandemic, with significant variation across states. Education losses from the pandemic are likely to be large and worsen pre-existing disparities; unless mitigated soon, they could contribute to heightened scarring over the medium term. Using state-level and cross-country comparisons, this paper reviews key social programs as well as priorities in education and health. It finds that higher spending and improved design of social programs (e.g., better targeting) would reduce socioeconomic gaps, mitigate scarring risks, and foster inclusive growth.
\end{abstract}

JEL Classification Numbers: I30, I38, I20, I28, I10, I18

Keywords: social programs, health, education, sustainable development goals.

Authors’ E-Mail Addresses: sahmed@imf.org; jcuesta@imf.org; dbartolini@imf.org 


\section{Contents}

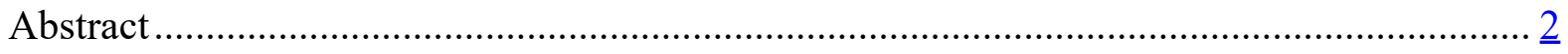

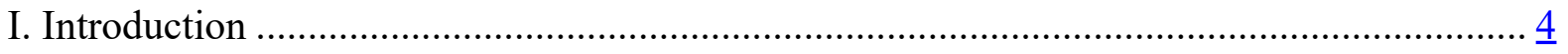

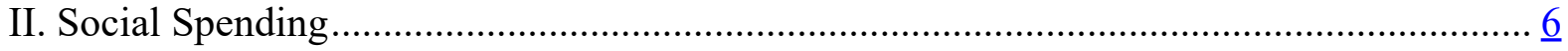

A. Social Protection

Social Assistance Spending ……………................................................................

Socioeconomic Disparities Prior to the Pandemic .......................................................... 7

The Government's Approach in 2019-24.................................................................... $\underline{8}$

Effectiveness of Social Programs .......................................................................... 10

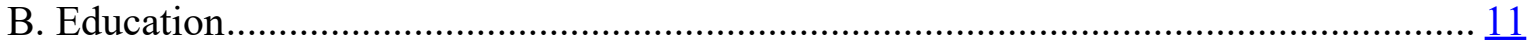

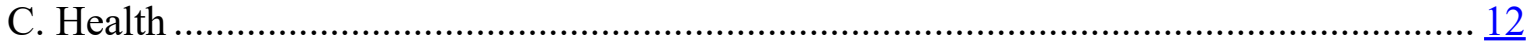

III. The Impact of COVID-19 ………………….................................................... 12

A. The Impact of Government Programs During the Pandemic......................................... 13

B. Pandemic, Scarring Risks, and Beyond ……………………………………….... 14

IV. Path to the Sustainable Development Goals (SDGs)..................................................... 15

A. Description of the Framework and SDG Needs....................................................... 15

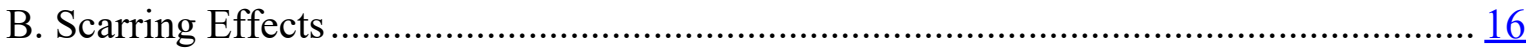

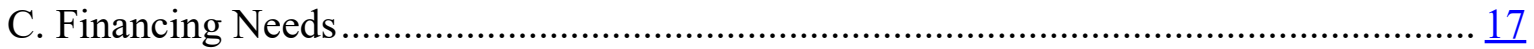

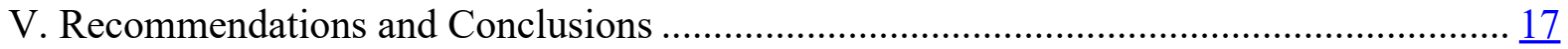

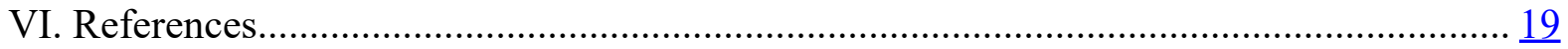

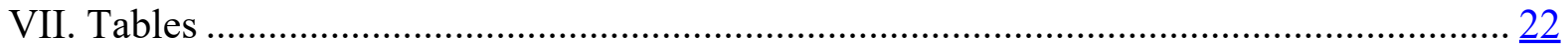

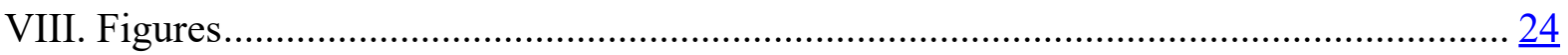




\section{INTRODUCTION ${ }^{1}$}

Poverty in Mexico was high before the COVID-19 pandemic. According to the country's National Council for the Evaluation of Social Development Policy (CONEVAL), more than 4 out of 10 people lived in poverty in Mexico before COVID-19. CONEVAL uses a multidimensional approach to measure poverty, which includes - apart from income - six indicators to capture social rights (educational gap; access to health services; access to social security; access to food; housing quality and space; access to basic housing services) and an indicator to capture degree of social cohesion. ${ }^{2}$ While both headline and underlying components of the poverty measure have generally improved between 2008 and 2018, 57.3 percent of the population still lacked access to social security in 2018, and around 20.4 percent lacked access to food, 16.9 percent lagged in education, and 16.2 percent lacked access to health services. The incidence of poverty was higher in rural areas and amongst indigenous population.

Following the pandemic, the poverty indicators worsened, from 41.9 percent to 43.9 percent between 2018 and 2020, implying that the number of people in poverty increased from 51.9 to 55.7 million. Worryingly, the lack of access to health services increased by 12 percentage points in the same timeframe. There is large state-level variation; for example, poverty in three states increased by over 8 percentage points. CONEVAL (2021a) finds that, absent social transfers, poverty indicators would have worsened even further to 45.9 percent. In other words, social transfers prevented a further 2.5 million people from falling into poverty in 2020 .

Going forward, scarring could be high, given the limited fiscal support provided during the pandemic, high informality, and low health spending - factors that were associated with high and persistent negative effects on inequality, unemployment, and poverty following past pandemics that were milder in reach and impact than COVID-19 (Cuesta Aguirre and Hannan, 2021). The substantial gap in internet coverage for children across income groups could also lead to school dropouts and education gaps, leaving a lasting impact on human capital accumulation, future job prospects, and inclusive growth.

\footnotetext{
${ }^{1}$ The authors would like to thank Rishi Goyal for his guidance; Laila Azoor for excellent editorial assistance; Sakai Ando, Jean-Marc Fournier, Tewodaj Mogues, Nikhil Patel, Nghia Piotr Le, Misa Takebe, Sebastien Walker, and Kevin Wiseman for helpful suggestions and comments; colleagues in the National Council for the Evaluation of Social Development in Mexico (CONEVAL) for useful discussions; and colleagues in the Secretaría de Hacienda y Crédito Público (SHCP, Mexico) for generous help with data, useful discussions, and helpful comments. All remaining errors are ours.

${ }^{2}$ Details on definition of poverty: https:/www.coneval.org.mx/InformesPublicaciones/FolletosInstitucionales/Documents/MultidimensionalMeasurement-of-poverty-in-Mexico.pdf. Definition of poverty and extreme poverty: https:/www.coneval.org.mx/Medicion/Paginas/Glosario.aspx. Poverty measurement, 2008-2018: https://www.coneval.org.mx/Medicion/MP/Paginas/Pobreza-2018.aspx. Poverty measurement, 2018-2020: https://www.coneval.org.mx/Medicion/MP/Paginas/Pobreza_2020.aspx.
} 
Against this background, the paper seeks to contribute to the discussion on inclusive growth in Mexico by assessing social spending, with a focus on the government's social programs. ${ }^{3}$ As Mexico's social programs underwent important changes in 2019, taking stock could point to policies to enhance effectiveness. Such consideration has taken on an urgency with the COVID-19 pandemic because of the disproportionate burdens placed on the vulnerable.

The paper's key findings are as follows. While progress has been made over time, poverty in Mexico remains stubbornly high and there remains substantial variation across states. Mexico's poverty rate is comparable to G-20 emerging markets (EM) and below Latin American averages. However, the share of income going to the poorest in 2018 was below the G-20 EM average. Around 40 percent of households with children/adolescents and a head (or spouse) of household of working age did not have social protection in 2018, higher than Latin American average (ECLAC-UNICEF, 2020a). Cross-sectional regressions using statelevel data suggest that higher spending on social programs, which was predominantly budgeted before the pandemic, helped to reduce poverty-highlighting the helpful role of policy to ameliorate COVID-19's impact.

There are notable shortfalls in education and health spending. Spending per student is well below the OECD average and somewhat below the EM average, as are the teacher-to-student ratio and the PISA score (Programme for International Student Assessment). There is substantial variation in education outcomes and quality across states, with a strong correlation between income per capita and literacy rates. There are also significant gaps in internet usage across income groups, one of the highest in the region. Similarly, public spending in health was well below the OECD and somewhat below the EM average, with substantial variation in access to health care across states. A frontier analysis that relates inputs to outputs suggest that there is room to improve quality and efficiency in education and health.

A comprehensive and coherent approach is needed to foster inclusive growth and address key challenges (e.g., high informality, regional disparities). Higher spending for social programs, education, and health would help reduce socioeconomic gaps, mitigate pandemic-induced scarring, and foster an inclusive recovery. Although more resources are likely needed to make satisfactory progress toward the Sustainable Development Goals (SDGs), spending increase of around 2 percent of GDP over the medium term for social programs, education, and health would constitute a meaningful and pragmatic start. There would also need to be a gradual increase in revenue collections over the medium term that ensures debt/GDP declines over the medium term and finances the higher spending.

Consideration should also be given to improving the design of programs and seeking greater efficiencies. Social programs in Mexico have significant gaps in coverage, overlaps in beneficiary lists, and fragmented programs. Targeting could be improved through community-based methods, new instruments (e.g., mobile money), adopting a single registry of beneficiaries, reducing overlaps in programs and benefits, and strengthening

\footnotetext{
${ }^{3}$ Unless otherwise stated, the social programs covered in the paper include social assistance and active labor market programs. Unless otherwise reported, social assistance include transfers, social pensions, public works, fee waivers and subsidies, and other social assistance.
} 
administrative capacity. The government's emphasis on (non-contributory) social pensions partly reflects the prevalence of old-age poverty, limited coverage of the pension system, and low replacement rates. However, while the 2018 social pensions were low in OECD comparison, the planned 2024 levels are relatively high.

The rest of the paper is organized as follows. Section II discusses social programs and health and education spending. Section III discusses the potential impact of COVID-19 on socioeconomic outcome and the role of policies. Section IV discusses the path to the SDGs. Section V discusses policy recommendations and concludes.

\section{Social SPENDing}

Social spending in Mexico was 10.9 percent of GDP in 2019, declining from its historical peak of 12.1 percent of GDP in 2015 (Figure 1). ${ }^{4}$ Around 40 percent of the spending goes to social protection while education and health comprise 27 and 23 percent, respectively; the remainder is for housing and community support and environmental preservation. In 2020, the social spending increased to 12.4 percent of GDP, but that mainly reflects the sharp drop in nominal GDP. Both the nominal and real growth of social spending was lower in 2020 compared to 2019. From a cross-country perspective, Mexico's social spending lags behind regional peers, partly reflecting its low revenue-to-GDP ratio.

\section{A. Social Protection}

Social protection spending usually includes social insurance and social programs. The former is designed to protect households from adverse shocks that affects incomes and welfare and is typically financed by contributions or payroll taxes. The latter is designed to protect households from poverty and is financed by general government revenue.

\section{Social Assistance Spending}

The overall social assistance in Mexico declined from 2.5 percent of GDP in 2015 to around 1.8 percent of GDP in 2018 (Figure 2). Looking at the components, transfers to individuals and households decreased over time, from 0.9 percent of GDP in 2015 to 0.5 percent of GDP in 2018 , due to the decline in both conditional and unconditional transfers. ${ }^{5}$ Around 61 percent of total social assistance funding went to fee waivers and subsidies in 2018, followed by around 28 percent in transfers and 8 percent in social pensions (Figure 3 ). There is considerable variation across states (Figure 4). Overall, states with higher poverty rates and

\footnotetext{
${ }^{4}$ Social spending usually includes social protection, education and health services (IMF, 2019a). As shown in Figure 1, the numbers reported include social protection, education, health, housing and community services, environmental protection, and others.

5 Transfers to individuals and households can be conditional (given with the requirement that the recipient meets certain conditions), unconditional (no requirements in terms of how they are spent or any condition related to when they are received), and food and in-kind. Fee waivers are usually subsidized services for the poor; subsidies are usually used to keep prices low for selected goods and services. Social (non-contributory) pensions are direct and regular payments for people above a certain age. For further details, see https://gsdrc.org/topic-guides/social-protection/types-of-social-protection/.
} 
lower income per capita received higher amounts of social assistance from the federal government when expressed as a share of state GDP (Figures 5 and 6).

\section{Socioeconomic Disparities Prior to the Pandemic}

Though declining over time, the poverty rate in Mexico remains stubbornly high with large variation across states. The modest decline in poverty reflects low economic growth and significant differences in growth and income across states (World Bank 2020). There are large persistent differences in income between the industrialized north and the less welldeveloped south. In particular, the rural areas experience low productivity, low investment in both physical and human capital, and high poverty rates.

The poverty rate - taking CONEVAL's estimates that employs a multidimensional concept of poverty encompassing six development indicators as described in the introductiondeclined between 2008 and 2018 across most states, leading to a decline in the overall poverty rate from 44.4 percent to 41.9 percent (Figure 7 ). The poverty rate increased in some of the states with relatively lower income per capita (Oaxaca and Veracruz). In addition, the poverty rates across states differ considerably, ranging from 14.5 in Nuevo Leon and 18.1 in Baja California Sur — both states with relatively higher income per capita - to 76.4 in Chiapas and 66.4 in Oaxaca — both states with relatively lower income per capita. Similarly, the overall extreme poverty rate declined from 11.0 to 7.4 percent between 2008 and 2018, underpinned by the decline across most states. However, there remains large variation across states with the lowest extreme poverty in Nuevo Leon (0.5 percent in 2018) and the highest in Chiapas (29.7 percent). While declining over the same time period in Oaxaca, the extreme poverty rate in Veracruz increased from 16.8 to 17.7 percent.

Compared to other countries, World Development Indicators (WDI; World Bank) data suggest that Mexico's poverty rate (using poverty headcount ratio at $\$ 1.90$ a day) is slightly higher than the G20 EM average, lower than Latin American peers like Brazil and Colombia, but higher than emerging markets like Chile, Thailand, Uruguay (Figure 8). Using the poverty headcount ratio at $\$ 3.20$ a day, Mexico's poverty rate is slightly lower than the G20 EM average. Similar trends are witnessed for the poverty gap, which measures the intensity of poverty. ${ }^{6}$ However, though improving from 4.6 percent in 2004 to 5.4 percent in 2018, the income share of the poorest in 2018 was lower than G-20 EM averages but higher than Latin American averages. The share of income for the poorest is above Latin American countries like Brazil and Peru but below emerging markets like Poland, India, and Thailand.

ECLAC-UNICEF (2020a) analyzed the coverage of the contributory and non-contributory components of social protection on households with children and adolescents where the head of the household and/or spouse is of working age (15-64 years) using data from around 2018. It found that 40 percent of households in Mexico do not have any protection, 34 percent have contributory protection, 22 percent non-contributory protection, while 4 percent have mixed protection. The percent of households with no protection is significantly larger than the Latin America aggregate of 33 percent and some regional peers (Argentina and Brazil, 21; Chile,

\footnotetext{
${ }^{6}$ According to WDI: poverty gap at $\$ 1.90$ a day ( $\$ 3.20$ a day) is the mean shortfall in income or consumption from the poverty line $\$ 1.90$ a day ( $\$ 3.20$ a day), expressed as a percentage of the poverty line. The non-poor are counted as having zero shortfall.
} 
and Costa Rica, 15), but lower than Colombia (44) and Peru (58). The contributory protection is also lower than the Latin America aggregate, while the non-contributory protection is higher Latin America aggregate. The share of protection is also low in Mexico given the country income per capita (Figure 9), with the share of households with no social protection higher than that compared to other countries considered in the analysis and the share of contributory protection and mixed protection lower given the level of income per capita.

\section{The Government's Approach in 2019-24}

The government's social programs since 2019 have focused on universal coverage and social (non-contributory) pensions. They have emphasized support to indigenous groups, the elderly, and people with special needs. The guiding principles are: ${ }^{7}$

(i) Priority will be given to people living in areas with a majority indigenous and AfroMexican population, areas with a high degree of marginalization or those with high rates of violence;

(ii) Financial and in-kind support will be delivered directly without intermediaries, preferably by bank instruments;

(iii) A single beneficiary registry will be integrated, to be continuously reviewed for validation, updating, and auditing;

(iv) Actions will be taken to identify the beneficiaries and the geographic location; and

(v) There will be specific mechanisms for community participation and social comptrollership.

In practice, this resulted in both an increase of overall spending on social assistance programs from 1.8 percent of GDP in 2018 to 2.1 percent of GDP in 2019 as well as reallocation in resources (Figures 2 and 3). Notably, social pensions increased sharply from 0.15 percent of GDP in 2018 to 0.50 percent of GDP in 2019, while transfers to individuals and households decreased marginally from 0.50 percent of GDP in 2018 to 0.35 percent of GDP in 2019 . With the changes, the share of transfers in total social assistance programs decreased from 28 percent in 2018 to 17 percent in 2019.

Delving deeper, the changes in the approach of social policies resulted in both an introduction of new programs as well as changes in allocation of resources in existing programs (Table 1). Broadly speaking, the programs have changed with the goal of a more universal coverage and reduction in the intensity of conditionality. The IMSS-Bienestar program that offers free health services continues to receive the most funding. However, the share of funding has decreased from 31 percent in 2018 to 25 percent in 2019 and $2020{ }^{8}$

\footnotetext{
${ }^{7}$ Details can be found in Programa Sectorial Bienestar 2020-2024 and Plan Nacional de Desarrollo 2019-2024.

${ }^{8}$ Total funding refers to the money allotted to social assistance programs and active labor market policies (ALMP).
} 
Two previous well-known social programs have been discontinued and replaced: (i) The Seguro Popular - the public health insurance program that used to cover a wide range of services without co-pays for its affiliates - was discontinued in 2020. It was replaced by Institute for Health for Wellbeing (INSABI) that aims to establish fully funded, integrated public health networks, cancelling all private subcontracting and offering free and universal services; and (ii) Prospera - which provided direct payments to poor families in exchange for children attending school and regular health checks and was the second largest program in 2018 - has been discontinued.

There are now three scholarship programs depending upon education levels, each receiving around 4-5 percent of total funding (Gomez, 2020). The first one, Benito Juárez Basic Education Welfare Scholarship program, are for families living in poverty and with children who study in initial, preschool, primary, or secondary education (under 15 years of age). There is no conditionality related to health or nutrition. Unlike Prospera that had paid per student, the payment for this program is per family; this is an important change as well that bears close observation to ensure school dropouts do not increase in the context of the COVID-19 pandemic. The second program, Benito Juárez Universal Scholarship Program, is targeted towards students who are in Higher Secondary Education in public institutions. The third one is a new active labor market program, Young People Writing the Future, which links people aged 18 to 29 who do not study or work with companies (workshops, institutions, etc.) to develop skills to improve future employability. The program provides monthly support and medical insurance up to one year.

The other notable change has been the increase in social (non-contributory) pensions. The emphasis on social pensions partly reflects the prevalence of old-age poverty as well as the limited coverage of the pension system, particularly for women, and low replacement rates. CONEVAL's multidimensional poverty approach indicates that 34.4 percent of the elderly are in moderate poverty and 8.8 percent in extreme poverty in $2018 .{ }^{9}$ Based on OECD data, the elderly experience higher poverty rates and a greater intensity of poverty (Figures 7.2 and 7.3 in OECD Pensions at a Glance (2019)). Social pensions rose by more than threefold, from 36 billion pesos in 2018 to 129 billion pesos in 2020, in the social program Pensión para el Bienestar de las Personas Adultas Mayores (previously called Pensión para Adultos Mayores). The program now receives the second largest funding, with the share of funding increased from 8 percent in 2018 to around 20 percent in 2019 and 2020 . The rise in funding is due to the more than doubling of the monthly payments, from 580 pesos per month in 2018 to 1275 pesos per month (2550 pesos bimonthly) in 2019 (DOF 2019). As of July 2021, the monthly payments are at 1550 pesos per month. Going forward, the President has announced that the payments will be increased further with the target of 3000 pesos per month (or 6000 pesos bimonthly) by 2024. In addition, the government has decreased the minimum age from 68 to 65 years. Previously, the minimum age was 65 years for the indigenous population and 68 years for other adults. These measures would increase the budgetary cost from around 136 billion pesos in 2021 (approved budget) to around 240, 300, and 370 billion pesos in 2022, 2023 , and 2024 respectively; translating into an increase of around 0.6 percentage points of GDP from 2021 to 2024.

\footnotetext{
${ }^{9}$ As discussed later in the paper, elderly poverty rates improved in 2020.
} 


\section{Effectiveness of Social Programs}

As outlined in Hannan et al. (2020), a good social assistance program usually has four characteristics: (i) it provides broad coverage and adequate benefits to vulnerable groups in a progressive way within the overall tax-benefit system; in other words, it gives more generous benefits to the poorest beneficiaries; (ii) it is cost effective by avoiding program fragmentation and beneficiary overlaps; (iii) it preserves work incentives and enhances human capital accumulation by linking transfers to programs such as public works, obtaining health care, and attending education and training; and (iv) it is financially sustainable within the overall expenditure envelope and consistent with other social protection programs.

Against these yardsticks, compared to medians of regional peers and emerging markets, Mexico's performance is mixed. On one hand, it significantly lags in coverage (share of population that receives a benefit), both for all social protection and labor programs in general and social assistance programs in particular (Figure 10). The benefits incidencepercentage of benefits going to each quintile relative to the total benefits going to population - for the poorest quantile is lower than most regional and EM medians in social assistance programs (Figure 12). On the other hand, the adequacy of benefits - the amount of transfers received as a share of the total income/expenditure of beneficiaries - is comparable to regional and EM medians for all social protection and labor, and better than the comparator groups for social assistance programs (Figure 11). However, the benefits incidence for social assistance programs is comparatively high for high income group. Finally, the beneficiary incidence - the percentage of beneficiary in each quintile relative to total beneficiaries across all quintiles - is comparatively better than the comparator groups.

Early evidence suggests that, in contrast to the principles behind the government's new strategy, many of the programs had little or no operational structures (CONEVAL, 2020a). ${ }^{10}$ The government's development plan emphasizes that the Federal Government should link and coordinate across institutions, strategies, programs and actions to secure continuous and holistic or mutually reinforcing development processes. However, during CONEVAL's fieldwork, there was limited evidence of coordination in the planning process (e.g., Coordination of Development Programs (CGPD) and Welfare Secretariate (SEBIEN)) on objectives, goals, work plans, and mechanisms of programs. This may reflect the need for better training and adequate knowledge and expertise in the programs, for adequate resources, and for ensuring efficient coordination processes between the central planning units and those responsible for programs implementation.

Early evidence from CONEVAL also suggests the need for better targeting the relevant population within the countries. Most of the high-priority programs operate on a geographical or territorial basis aimed at places with high and very high marginalization , indigenous people, and the greatest levels of violence. However, territories of high and very high marginalization may have people with different poverty levels, the data on marginalization are out-of-date compared to poverty data, and CONEVAL found no evidence of prioritizing by areas of violence.

${ }^{10}$ CONEVAL conducted design evaluations with fieldwork for 17 programs during 2019-20. 
Before 2019, non-contributory benefits were a smaller share of earnings in Mexico than in other countries (Figure 13). The increase in social or non-contributory pensions was thus needed, particularly given the prevalence of old-age poverty. However, while the 2018 social pensions were low in OECD comparison, the planned 2024 levels are relatively high, controlling for per capita incomes.

Prospera's predecessors, Progresa and Oportunidades, were found to have positively impacted school enrolment, education and health levels, and nutritional status, and helped reduce poverty in rural areas (World Bank, 2014, Parker and Vogl 2018). However, it was also found that these programs could have been further improved to address concerns about targeting, exclusion errors, and corruption (Bearman 2019, Covarrubias 2018). As noted by CONEVAL (2020b), programs with similar interventions of payment per family as the government's new program Benito Juárez Basic Education Welfare Scholarship had opposite effects on the school attendance rate of the other members. Hence, it is important to monitor and take steps to ensure that attendance is not affected, particularly for girls. In addition, policy should remain vigilant that health and nutrition do not get negatively affected due to the removal of conditionality in this regard. These issues take on added importance in the pandemic context where school dropout and economic scarring are risks (see below).

\section{B. Education}

Given the constitutional mandate to universalize secondary education, there is likely to be an increasing demand for education services and a sector-wide shift toward secondary and tertiary levels (IMF, 2019b). Such demand could add to fiscal pressures that would need to be coupled with increasing efficiency to enhance the value of education spending.

To assess the need for increasing both the resources and their efficiency in education, education expenditure and outcomes in Mexico are compared with peers and a frontier analysis is conducted. The government's education expenditure, as a share of GDP, is in line with OECD and other comparator groups, EMs and the Latin America (LA) averages (Figure 14) ${ }^{11}$ However, education expenditure per student is well below the OECD average and somewhat below EMs, but higher than LA. The primary and secondary teacher-to-student ratios (per 100 students) are well below the OECD average, especially in primary for which it is below EM and LA and also below the secondary teacher-to-student ratio of Mexico.

The frontier analysis - analyzing the relationships between different combinations of inputs and outputs by education level - suggest that, though higher than many LA countries, there is room for efficiency gains in Mexico, particularly in the secondary enrollment (second and third row charts of Figure 14). ${ }^{12}$ Finally, the adult literacy rate is below OECD but above EM and LA, while the PISA score is well below the OECD average, slightly below EM, and higher than LA.

\footnotetext{
${ }^{11}$ Education expenditure varies using national source (functional classification within budget, reported by Hacienda) and that reported by WDI. The former includes the federal government, while the latter also includes states and municipalities.

${ }^{12}$ The efficiency frontier is calculated using Data Envelopment Analysis (DEA). For further details, see IMF Expenditure Assessment Tool (EAT) and the underlying technical note.
} 
The educational outcome and quality varies substantially across states in Mexico with a strong correlation between income per capita and literacy rate across states (Figure 15). States like Mexico City and Colima have higher than 7 teachers per 100 students in education, while Tabasco and Puebla have 5 teachers per 100 students. The dropout rates across different education levels also vary considerably across states.

\section{Health}

The total health spending in Mexico has declined by around 1 percentage point of GDP over time, from 6.4 percent of GDP in 2009 to 5.5 percent of GDP in 2018 (Figure 16). Within that envelope, the share of public spending increased from 46.7 percent in 2009 to 53.2 percent in 2014, and then declined to 50.1 percent in 2018.

The total health expenditure in Mexico was lower than OECD and EM/LA averages, 5.5 percent of GDP in Mexico in 2018 compared to 8.9 percent of GDP in OECD, 6.6 in EM, and 7.5 in LA. The public health expenditure, both as a share of GDP and as a share of total health expenditure, is also lower in Mexico compared to these groups. Correspondingly, the total health expenditure per capita is significantly below OECD and somewhat below/comparable to EM and LA averages. The number of hospital beds, nurses, and physicians (per 1000 persons) are also lower than OECD. As for education, Mexico is also below the health efficiency frontier suggesting that there is room for increasing the quality and the efficiency of the health services.

There is also substantial variation across states on health indicators. More than 80 percent of the population is affiliated to health services in states like Chihuahua, Baja California Sur, Colima, and San Luis Potosi. However, less than 70 percent of the population is affiliated to health services in states like Jalisco, Hidalgo and Chiapas (Figure 17). The lowest coverage, at 62.2 percent of population, is in Michoacan de Ocampo. A higher proportion of females is affiliated to health services, compared to men.

\section{THE IMPACT OF COVID-19}

The pandemic shock could significantly exacerbate the pre-existing vulnerabilities discussed above. While data come out with a lag, early indicators are worrisome. The national labor poverty spiked by 7 percentage points between Q42019 and Q32020, and then decreased (Figure 18). ${ }^{13}$ At 40.7 percent in Q42020, it remained 3.4 percentage points higher than prepandemic levels. The national figure masks large state level variation, with the labor poverty rate in Quintana Roo, Mexico City, and Tabasco increasing by more than 10 percentage points between Q42020 and Q42019 and eight additional states witnessing an increase in poverty rates of more than 5 percentage points during the same period. In Q22021, the labor poverty rates of three states were 5 percentage points above Q42019 levels, and additional eighteen states had positive increases. The poverty rate across most states in 2018 was higher for women compared to men (CONEVAL, 2020c), and, together with the increase in

\footnotetext{
${ }^{13}$ Labor poverty is the percentage of population with labor income lower than the cost of the food basket (https://www.coneval.org.mx/Medicion/Paginas/Glosario.aspx).
} 
indicators like domestic violence and gender violence in 2020 (Figure 18), suggest more hardships for females.

Using an updated measurement of poverty, CONEVAL (2021b) finds that poverty rate increased from 41.9 percent to 43.9 percent between 2018 and 2020, implying the number of people in poverty increased from 51.9 to 55.7 million. ${ }^{14}$ The number of people in extreme poverty increased from 7.0 to 8.5 percent in the same time period, indicating that the number of people increased from 8.7 to 10.8 million. The lack of access to health services increased by 12 percentage points in the same timeframe. ${ }^{15}$ Having said that, the poverty amongst elderly people decreased by 5.3 percentage points, from 43.2 percent to 37.9 percent in the same period; and rural poverty fell from 57.7 percent to 56.8 percent. There are large statelevel variations with poverty in three states increasing by over 8 percentage points. However, poverty rate decreased in the range of 1.5-2.7 percentage points in the four states with the highest historical incidence of poverty (Chiapas, Guerrero, Oaxaca, and Veracruz). ECLACUNICEF (2021b) projections suggest that Mexico witnessed one of the highest increases in poverty in 2020, in absolute levels and for the given level of income per capita (Figure 19).

\section{A. The Impact of Government Programs During the Pandemic}

The authorities responded to the pandemic by increasing health spending and direct budget support to households and firms by 0.7 percent of GDP and raising below-the-line measures and contingent liabilities by 1.2 percent of GDP. This support was lower than emerging market economies' direct and below-the-line budget support of 4.1 and 2.6 percent of GDP respectively (IMF Fiscal Measures Database, July 2021). Although the government's response to the pandemic was muted to contain the increase in public debt, the increase in social program spending, which was predominantly budgeted before the pandemic, appears to have ameliorated somewhat the effect of the pandemic on poverty.

To assess the impact of social program spending on economic activity and poverty, we run cross-sectional regressions on state-level data for 2020. The 2020 change in economic activity (employment, retail sales) and poverty (labor poverty) are regressed on the change in social program spending in 2020 (actual 2020 minus actual 2019, divided by 2019 GDP), controlling for state-level income per capita, tourism and export exposures, population density, mobility, cases per capita, and lagged dependent variable.

The results, presented in Table 2, suggest that an increase in social program spending across states were associated with positive effects on employment, retail sales, and labor poverty. All else equal, a state that increased spending by 0.27 percentage points of GDP $\left(75^{\text {th }}\right.$ percentile) increased employment by 5.4 percent, while a state that increased spending by 0.15 percentage points of GDP $\left(25^{\text {th }}\right.$ percentile) increased employment by 3.1 percent (Figure

\footnotetext{
${ }^{14}$ The updated methodology keeps the same foundations and the definition of multidimensional poverty. These updates imply changes in the definition of the thresholds or the construction of the indicators. The new series is not directly comparable to the previous one. For more information, refer to CONEVAL (2021b).

${ }^{15}$ This could potentially reflect low awareness of universal access to INSABI during the transition from Seguro Popular to INSABI. This would suggest, at a minimum, room for improvement in communication, so the population is aware of the free health care offered by INSABI.
} 
20). However, the effects are found to be higher for male than female employment. Similarly, retail sales increased by 2.8 percent for the $75^{\text {th }}$ percentile, compared to 1.6 percent for the $25^{\text {th }}$ percentile; though the results are not statistically significant for retail sales. Importantly, the labor poverty reduced by around 4.5 percentage points for the $75^{\text {th }}$ percentile compared to 2.6 percentage points for the $25^{\text {th }}$ percentile. These correlations suggest that higher support would have helped to limit the negative effects on economic activity and poverty even more.

In line with Cuesta Aguirre and Hannan (2020), the regression results also suggest that states that were more exposed to tourism got more affected, with the drop in retail sales and the increase in poverty rates higher for the more tourist-exposed states. All else equal, states with higher population density also got more affected. Note that the analysis looks at the change in the 2020 outcome versus the 2019 outcome, which included both planned and, among other factors, COVID-19 related increases. Federal level aggregate data suggest that a significant portion of the increase was already budgeted pre-pandemic.

\section{B. Pandemic, Scarring Risks, and Beyond}

Though rebounding strongly in 2021, Mexico's 2020 output drop was not only historic but also one of the largest among G20 and regional peers. With limited fiscal support during the pandemic - a factor that has been crucial in combating the pandemic in countries (IMF 2021a, IMF 2020) - the scarring or damaging effects of the crisis could be long lasting in Mexico, particularly due to the presence of high informality and the relatively limited recourse to social safety nets.

Although COVID-19 was a larger shock than other pandemics in recent years, the increases in unemployment, poverty, and inequality following past pandemics have been found to be lower for countries with relatively greater fiscal support and relatively lower informality, higher family benefits, and higher health spending (Cuesta Aguirre and Hannan, 2021). Given Mexico's limited fiscal support, high informality and low health expenditure, these results point towards heightened scarring risks for the country.

Certain COVID-19 specific effects elevate scarring risks. The pandemic has resulted in the largest disruption of education systems in history, affecting nearly 1.6 billion people in more than 190 countries (UN, 2020), and exacerbated pre-existing education disparities. Using data on 174 countries, Azevedo et al. (2021) find that school closures could result in a loss of 0.3 and 1.1 years of schooling adjusted for quality and close to 11 million students from primary and secondary education could drop out due to the income shock of the pandemic. Exclusion and inequality are likely to be worsened if the already marginalized and vulnerable groups (girls, ethnic minorities, and persons with special needs) are more adversely affected by school closures.

The social distancing during the pandemic meant reliance on online schooling globally. In that regard, there is a significant gap in internet coverage for children across income groups (Figure 21). For example, for 15-year-old students, the access to the internet at home is in line with the Latin American average for the top income bracket but 25 percentage points lower for the fourth quartile. Consequently, the gap of internet access for 15-year old 
students across income groups is the highest in Mexico (alongside Panama) and above the Latin American average.

Similarly, the gap in internet access through mobile is the highest in the region. 88.8 percent of children in Quintile I lack access to internet - the second highest in that income group for the countries considered - compared to 18.4 percent in Quintile V. These significant gaps in internet access across income groups could lead to school dropouts and education gaps (CONEVAL, 2020), impairing human capital accumulation and future job prospects. Apart from requiring resources to address pre-existing disparities in educations, schools would thus urgently require resources to rebuild the loss in learning during the pandemic (Burgess and Sievertsen, 2020), including priority to programs that address school dropouts.

\section{Path to the Sustainable Development Goals (SDGs)}

The previous sections have highlighted the pre-pandemic disparities in Mexico across a range of development indicators (both compared to other countries for the given income per capita and across states) and how the pandemic is likely to exacerbate these disparities and have a lasting impact on key areas, including human capital. This section explores what that means for Mexico's prospects of reaching the Sustainable Development Goals in five key areas (education, health, roads, electricity, and water and sanitation) and risks of scarring on longterm income per capita and the financing needs owing to the pandemic. This section uses a dynamic macroeconomic framework centered on the roles of the public and private sector to generate funding to achieve SDG goals in these five areas.

While the model results are for illustrative purposes only, the findings of this section suggest that: (i) Mexico would need additional resources to meet satisfactory progress in meeting the SDGs; (ii) these additional needs have increased due to the pandemic. In particular, the financing needs are likely to be even higher than what is presented in the baseline due to the scarring effects associated with human capital destruction during the pandemic, and (iii) apart from increasing financing needs, the long-term income per capita could be lower, owing to the human capital destruction/scarring effects of the pandemic.

\section{A. Description of the Framework and SDG Needs}

The SDG Financing tool (see IMF, 2021b) is a framework to evaluate financing needs to achieve SDGs in a macroeconomically consistent and dynamic setting. The tool allows to monitor the performance of the economy on funding SDGs in five key development areas (i.e., education, health, roads, electricity, and water and sanitation), and to assess alternative financing options. The tool is dynamic with projections up to 2050, and with a production function which assures output is consistent with spending in human capital (education and health) and physical capital (roads, electricity, water and sanitation). The simulations include a set of accounting identities throughout the real, fiscal, and external sectors to ensure macroeconomic consistency.

The assessment of SDG needs in human capital and physical infrastructure are taken as given, and then, using different scenario assumptions, the tool is used to determine how large the remaining financing gap is on average between the current and the target years. For 
health and education, the level of spending required to reach satisfactory progress towards the SDGs is taken from IMF (2019b): 6.4 percent of GDP for health and 6.6 percent of GDP for education. Using the input-output methodology of Gaspar et al. (2019), IMF (2019b) follow three steps to derive these targets: (i) identify key inputs and the associated unit cost in health and education sectors; (ii) benchmark the input costs in Mexico to countries with comparable GDP per capita levels but higher social outcomes; and (iii) estimate the spending levels needed to achieve those high-quality outcomes, given Mexico's GDP per capita and population growth. The estimates are computed for 2030 and compared to the 2019 levels to determine the "gap" that needs to be closed.

The gaps for roads, electricity, and water and sanitation are taken from Global Infrastructure Outlook (2017). The investment need forecast by Global Infrastructure Hub (GIH) is computed based on a panel data approach that predicts the level of investment needed if Mexico invested as much as its peers with the highest investment ratios, after controlling for country characteristics. Mexico's gap in roads - needs minus 2007-2015 actual—is found to be 1.15 percent of GDP (for detailed discussion, see IMF $2019 \mathrm{~b}$ and Global Infrastructure Outlook 2017).

GIH also developed models to estimate how much the countries need to spend on electricity and water infrastructure to meet SDG objectives of "ensuring availability and sustainable management of water and sanitation for all" and "ensuring access to affordable, reliable, sustainable and modern energy for all". The model creates a direct link between the value of spending, expected population change, and access to electricity, water and sanitation. The spending requirements to meet SDG for electricity and water and sanitation are estimated to be 0.4 and 0.2 percent, respectively.

Before proceeding to results, few caveats should be acknowledged. As is the case in these sorts of exercises using dynamic models, it must be cautioned that the model results are sensitive to the assumptions. As such, the model results should be regarded as illustrative only. In particular, the SDG estimates could be sensitive to assumptions. At the same time, they are likely to be lower bounds given they are pre-pandemic estimates.

\section{B. Scarring Effects}

As discussed previously, the pandemic may leave a lasting impact in Mexico, particularly due to the high labor informality, limited recourse to safety nets, and the uneven internet access across the country. Correspondingly, scarring may be associated with factors like schooling interruptions, unemployment due to skills mismatches and closing of in-person activities in the service sector, and lower returns to spending on education due to social distancing. We calibrate four parameters of the above-mentioned endogenous growth model in Mexico's dynamic financing framework to capture these effects: human capital depreciation (e.g., unemployment effects), diffusion (e.g., difficulty of young people to enter the labor force), and two efficiency parameters on the return to education (e.g., the difficulty of creating human capital in a remote-type learning model).

Using this set-up, the baseline is determined, and two scenarios are conducted where all the four parameters mentioned in the previous paragraph are worsened by 5 percent and 10 
percent. The model simulations suggest that long-term real GDP per capita could drop by about 4.5 percent over the long-term (2050) owing to COVID-19 if the scarring effects are 5 percent (Figure 22). The deterioration in real GDP per capita would be even more pronounced under the assumption of 10 percent scarring effects. While these are just illustrative scenarios, the findings suggest that, if unaddressed, the pandemic-effects could lead to substantial long-term deterioration in income per capita.

\section{Financing Needs}

This framework suggests that Mexico would need additional financing of around 4.6 percent of GDP per year to meet satisfactory progress toward the SDGs by 2030 in the five areaseducation, health, roads, electricity, water and sanitation. The scarring effects discussed previously, if materialized, are likely to further increase the funding needs by around 0.2-0.4 percentage points of GDP.

This is a large amount of additional spending that, on one hand, will yield important benefits to Mexico but, on the other hand, requires raising adequate resources for financing and ensuring debt/GDP declines over the medium term. Given that Mexico significantly lags OECD countries and regional peers on non-oil tax collections, medium-term tax reforms - to be implemented gradually as the economy strengthens - would be necessary to finance these needs (particularly, if the increased tax revenues are used for development purposes) and reduce public debt/GDP.

\section{RECOMMENDATIONS AND CONCLUSIONS}

The social needs to reduce poverty and improve education and health were important before the pandemic, while the pandemic has made it even more urgent to act decisively to narrow gaps, limit scarring, and make satisfactory progress toward the Sustainable Development Goals. Both the amount of spending and the efficiency of spending across social protection, health and education need to be increased.

In this context, a comprehensive approach involving greater spending and efficiency is recommended. Although the financing required to make progress on the SDGs in key areas is large (above 4 percent of GDP), budget constraints and the likely feasibility of raising sufficient revenues in a timely manner also need to be considered. As a pragmatic initial step, consideration could be given to enhancing spending for social assistance, education and health for about 2 percent of GDP over the medium-term - 1 percent of GDP for social assistance and 1 percent of GDP for education and spending over the medium term. The spending on quality physical infrastructure should also be increased to increase medium-term growth and productivity (IMF, 2019b). This higher spending should be a part of package that not only improves efficiency by addressing various challenges (e.g., gaps, overlaps, and fragmentation across social programs, high labor market informality) but also raises revenues through a medium-term tax reform that durably enhances collections as the economy strengthens. Given the large variation across states in education and health, access should be deepened in low-coverage areas and to disadvantaged population. 
Adaptations to the government's social program strategy are recommended to enhance their effectiveness. As noted, the social assistance programs in Mexico have significant gaps in coverage and include fragmented programs as well as overlapping beneficiary lists. Improved targeting with progressive transfers would seal leakage of benefits to high-income groups. Community-based methods and new instruments (e.g., mobile money) could be used to identify those in need and reach them. A single registry of beneficiaries and strengthened administrative capacity could reduce overlaps. Increased use of evidence-based analysis in designing or improving programs would further enhance effectiveness. As unemployment support in Mexico is limited, consideration could also be given to introducing a national unemployment scheme - building on the smaller-scale programs currently conducted by the national social security institute (IMSS), the ministry of social development, and the Mexico City government. The progressiveness of public transfers could also be improved to mitigate the impact on lower-income household of the drop in income following the pandemic (CONEVAL, 2021c).

Regarding education spending, greater efforts to enhance the efficiency of spending could yield important returns over the medium term. In particular, spending could be rebalanced toward investment in equipment and facilities, alongside payroll audits to identify ghost workers and curb absenteeism. Investment in equipment, facilities, information technology and modern infrastructure would help to pace with the evolving labor demands (IMF, $2019 b$ ). The quality of early-childhood education and access to education in low-coverage regions and for disadvantaged children should also be enhanced to improve outcomes and inclusion. Similarly, in health, the need for affordable and quality health services across the population is large and has become more acute with the pandemic. Consideration should be given to better targeting investment to impoverished areas with deficient access to services, alongside measures to decrease administrative and insurance costs and reduce beneficiary duplication. 


\section{REFERENCES}

Aguirre, Juan Pablo Cuesta, Swarnali Ahmed Hannan, 2021. "Recoveries After Pandemics: The Role of Policies and Structural Features," IMF Working Paper Series, WP/21/181 (Washington: International Monetary Fund).

Azevedo, Joao Pedro, Amer Hasan, Diana Goldemberg, Koen Geven, Syedah Aroob Iqbal, 2021. "Simulating the Potential Impacts of COVID-19 School Closures on Schooling and Learning Outcomes: A Set of Global Estimates," The World Bank Research Observer, 36 (1), pp: 1-40.

Bearman, Thomas, 2019. "Prospera and the future of social protection and education in Mexico," socialprotection.org, https://socialprotection.org/discover/blog/prosperaand-future-social-protection-and-education-mexico.

Burgess, Simon, Hans Henrik Sievertsen, 2020. "Schools, skills, and learning: The impact of COVID-19 on education," VoxEU.org, 01 April, https://voxeu.org/article/impactcovid-19-education.

CONEVAL, 2021a. "Medición multidimensional de la pobreza en México, 2018-2020," https://www.coneval.org.mx/Medicion/MP/Documents/MMP_2018_2020/Pobreza_m ultidimensional 20182020 CONEVAL.pdf.

, 2021b. "CONEVAL presents the multidimensional poverty estimates 2018 and 2020," Communication No. 09, https://www.coneval.org.mx/SalaPrensa/Comunicadosprensa/Documents/2021/COM UNICADO_009_MEDICION_POBREZA_2020.pdf?platform=hootsuite.

-, 2021c. "From emergency to recovery of the pandemic COVID-19: Social Policy in the Face of Disasters,"

https://www.coneval.org.mx/Evaluacion/IEPSM/Documents/Politica_social atencion a desastres.pdf.

_ 2020a. "Informe do Evaluación De La Política De Desarrollo Social 2020," https://www.coneval.org.mx/Evaluacion/Documents/Informes/IEPDS 2020.pdf.

— Bienestar Benito Juárez," https://www.coneval.org.mx/SalaPrensa/Comunicadosprensa/Documents/2020/Comu nicado_12 BECAS_PARA_EL_BIENESTAR_EDUCACION_BASICA.pdf.

— , 2020c. "Panorama de los Programas y Acciones Sociales en las Entidades Federativas," https://www.coneval.org.mx/coordinacion/entidades/Documents/Panorama-COVIDdic_2020.pdf.

Covarrubias, Stephannie, 2018. "Enhancing PROSPERA to Reduce the Poverty Disparity Within the Indigenous Populations to Mexico,” McGill Perspectives on Global 
Health, http://www.perspectivesmcgill.com/opinion/2018/1/18/enhancing-prosperato-reduce-the-poverty-disparity-within-the-indigenous-populations-of-mexico.

ECLAC-UNICEF, 2020a. "Social protection for families with children and adolescents in Latin America and the Caribbean: An imperative to address the impact of COVID19," COVID-19 Report, https://www.cepal.org/en/publications/46490-socialprotection-families-children-and-adolescents-latin-america-and-caribbean.

_ 2020b. "Social Panorama of Latin America," https://repositorio.cepal.org/bitstream/handle/11362/46688/8/S2100149 en.pdf.

Gaspar, V., D. Amaglobeli, M. Garcia-Escribano, D. Prady, and M. Soto, 2019. "Fiscal Policy and Development: Human, Social, and Physical Investments for the SDGs," IMF Staff Discussion Note (Washington: International Monetary Fund).

Global Infrastructure Hub, 2017. "Global Infrastructure Outlook: Infrastructure investment needs 50 countries, 7 sectors to 2040," Oxford Economics, https://www.oxfordeconomics.com/recent-releases/99f4fa86-a314-4762-97c6fac8bdcbe40a.

Gomez, Katya Rodriguez, 2020. "From Progresa-Oportunidades-Prospera to the Benito Juarez Scholarships: a preliminary analysis of the changes in social policy in the sixyear period 2018-2024 in Mexico," Mexican Journal of Political Analysis and Public Administration, IX (1), pp. 81-91.

Hannan, Swarnali Ahmed, Keiko Honjo, Mehdi Raissi, 2020. "Mexico Needs a Fiscal Twist: Response to COVID-19 and Beyond," IMF Working Paper Series, WP/20/215 (Washington: International Monetary Fund).

IMF, 2021a. “A Fair Shot,” IMF Fiscal Monitor April 2021:

https://www.imf.org/en/Publications/FM/Issues/2021/03/29/fiscal-monitor-april-2021.

, 2021b. "A Post-Pandemic Assessment of the Sustainable Development Goals," IMF Staff Discussion Note, SDN/2021/003 (Washington: International Monetary Fund).

, 2020. "Fiscal Policy at the Time of a Pandemic: How have Latin America and the Latin America fared?" Regional Economic Outlook for Western Hemisphere, Chapter 4 (Washington: International Monetary Fund).

— 2019a. “A Strategy for IMF Engagement on Social Spending," IMF Policy Paper (Washington: International Monetary Fund).

_ 2019b. "Budget Spending Pressures,” Mexico Selected Issues (Washington: International Monetary Fund).

OECD, 2019. "Pensions at a Glance 2019," https://www.oecd-ilibrary.org/social-issuesmigration-health/pensions-at-a-glance-2019 b6d3dcfc-en. 
Parker, Susan W., 2018. "The long-term effects of cash transfers: Mexico's Progresa," VoxDev, https://voxdev.org/topic/public-economics/long-term-effects-cash-transfersmexico-s-progresa.

UN, 2020. "Education during COVID-19 and beyond," Policy Brief, August 2020: https://www.un.org/development/desa/dspd/wpcontent/uploads/sites/22/2020/08/sg policy brief covid19 and_education_august_2020.pdf.

World Bank, 2020. Poverty and Equity Brief for Mexico (Latin America and the Caribbean). https://databank.worldbank.org/data/download/poverty/33EF03BB-9722-4AE2ABC7-AA2972D68AFE/Global_POVEQ_MEX.pdf.

_ 2014. "A Model from Mexico for the World," https://www.worldbank.org/en/news/feature/2014/11/19/un-modelo-de-mexico-parael-mundo. 


\section{TABles}

Table 1. Top Social Programs in Mexico Over Time

\begin{tabular}{|c|c|c|c|c|c|c|c|}
\hline \multicolumn{4}{|l|}{2014} & \multicolumn{4}{|l|}{2018} \\
\hline Program & Category & $\begin{array}{l}\text { Amount } \\
\text { (MXN bn) }\end{array}$ & $\begin{array}{c}\text { Share of Total } \\
\text { Program Financing* }\end{array}$ & Program & Category & $\begin{array}{l}\text { Amount } \\
\text { (MXN bn) }\end{array}$ & $\begin{array}{c}\text { Share of Total } \\
\text { Program Financing* }\end{array}$ \\
\hline \begin{tabular}{|l} 
Atención a la Salud (IMSS) \\
\end{tabular} & Fee waivers and subsidies & 119 & $27 \%$ & Atención a la Salud (IMSS) & Fee waivers and subsidies & 133 & $31 \%$ \\
\hline PROSPERA Programa de Inclusión Social & сCT & 69 & $16 \%$ & PROSPERA Programa de Inclusión Social & CCT & 65 & $15 \%$ \\
\hline Seguro Popular & Fee waivers and subsidies & 68 & $15 \%$ & Seguro Popular & Fee waivers and subsidies & 64 & $15 \%$ \\
\hline Pensión para Adultos Mayores & Social Pension (non-contr) & 36 & $8 \%$ & Pensión para Adultos Mayores & Social Pension (non-contr) & 36 & $8 \%$ \\
\hline Programa de Fomento a la Agricultura & UCT & 25 & $6 \%$ & Atención a la Salud & Fee waivers and subsidies & 21 & $5 \%$ \\
\hline Atención a la Salud & Fee waivers and subsidies & 17 & $4 \%$ & Programa de Fomento a la Agricultura & UCT & 17 & $4 \%$ \\
\hline Atención a la Salud (ISSSTE) & Fee waivers and subsidies & 16 & $4 \%$ & Atención a la Salud (ISSSTE) & Fee waivers and subsidies & 17 & $4 \%$ \\
\hline Programa de Abasto Rural a cargo de Diconsa, S.A. de C.V. (DICONSA) & Food and in-kind transfers & 15 & $3 \%$ & Programa de Abasto Rural a cargo de Diconsa, S.A. de C.V. (DICONSA) & Food and in-kind transfers & 12 & $3 \%$ \\
\hline Programa de esquema de financiamiento y subsidio federal para vivienda (CONAVI) & Fee waivers and subsidies & 11 & $3 \%$ & Programa IMSS-PROSPERA & Fee waivers and subsidies & 12 & $3 \%$ \\
\hline Programa Nacional de Becas & UCT & 10 & $2 \%$ & Becas de posgrado y apoyos a la calidad & UCT & 10 & $2 \%$ \\
\hline \multicolumn{4}{|l|}{ on } & \multicolumn{4}{|l|}{2020} \\
\hline Atención a la Salud (IMSS) & Fee waivers and subsidies & 135 & $25 \%$ & Atención a la Salud (IMSS) & Fee waivers and subsidies & 158 & $25 \%$ \\
\hline Pensión para el Bienestar de las Personas Adultas Mayores & Social Pension (non-contr) & 113 & $21 \%$ & Pensión para el Bienestar de las Personas Adultas Mayores & Social Pension (non-contr) & 129 & $20 \%$ \\
\hline Seguro Popular & Fee waivers and subsidies & 68 & $13 \%$ & Atención a la Salud y Medicamentos Gratuitos para la Población sin Seguridad Social Laboral & Fee waivers and subsidies & 94 & $15 \%$ \\
\hline Jóvenes Construyendo el Futuro & Active LM programs & 28 & $5 \%$ & Beca Universal para Estudiantes de Educación Media Superior Benito Juárez & CCT & 32 & $5 \%$ \\
\hline PROSPERA Programa de Inclusión Social & CCT & 26 & $5 \%$ & Programa de Becas de Educación Básica para el Bienestar Benito Juárez & Other social assistance & 29 & $5 \%$ \\
\hline Beca Universal para Estudiantes de Educación Media Superior Benito Juárez & СCT & 25 & $5 \%$ & Sembrando Vida & Public works & 27 & $4 \%$ \\
\hline Atención a la Salud & Fee waivers and subsidies & 21 & $4 \%$ & $\begin{array}{l}\text { Jóvenes Construyendo el Futuro } \\
\text { S }\end{array}$ & Active LM programs & 25 & $4 \%$ \\
\hline Atención a la Salud (ISSSTE) & Fee waivers and subsidies & 17 & $3 \%$ & Atención a la Salud & Fee waivers and subsidies & 25 & $4 \%$ \\
\hline Sembrando Vida & Public works & 14 & $3 \%$ & Atención a la Salud (ISSSTE) & Fee waivers and subsidies & 21 & $3 \%$ \\
\hline Programa IMSS-PROSPERA & Fee waivers and subsidies & 12 & $2 \%$ & Programa de Abasto Rural a cargo de Diconsa, S.A. de C.V. (DICONSA) & Food and in-kind transfers & 14 & $2 \%$ \\
\hline
\end{tabular}


Table 2. State-level Regression Results: Impact of Change in Social Program Spending in 2020 on Economic Activity and Labor Poverty

\begin{tabular}{|c|c|c|c|c|c|c|}
\hline VARIABLES & $\begin{array}{c}\text { (1) } \\
\text { Employment, } \\
\text { Total } \\
\end{array}$ & $\begin{array}{c}\text { (2) } \\
\text { Employment, } \\
\text { Male }\end{array}$ & $\begin{array}{c}\text { (3) } \\
\text { Employment, } \\
\text { Female } \\
\end{array}$ & $\begin{array}{c}\text { (4) } \\
\text { Retail Sales } \\
\end{array}$ & $\begin{array}{c}(5) \\
\text { Labor Poverty } \\
1 / \\
\end{array}$ & $\begin{array}{c}(6) \\
\text { Labor Poverty } \\
2 / \\
\end{array}$ \\
\hline Change in social program spending (percent of lagged GDP) & $\begin{array}{c}0.2018 * * \\
(0.0744)\end{array}$ & $\begin{array}{c}0.1902 * * * \\
(0.0579)\end{array}$ & $\begin{array}{c}0.0805 \\
(0.1237)\end{array}$ & $\begin{array}{c}0.1034 \\
(0.0746)\end{array}$ & $\begin{array}{c}-17.2721^{* * *} \\
(5.1114)\end{array}$ & $\begin{array}{c}-16.4388 * * * \\
(5.3736)\end{array}$ \\
\hline Lagged GDP per capita (million pesos per capita) & $\begin{array}{c}0.0912 \\
(0.0804)\end{array}$ & $\begin{array}{c}0.0961 \\
(0.0652)\end{array}$ & $\begin{array}{l}-0.0182 \\
(0.1309)\end{array}$ & $\begin{array}{c}0.0075 \\
(0.0840)\end{array}$ & $\begin{array}{c}-3.6477 \\
(5.5306)\end{array}$ & $\begin{array}{l}-3.2974 \\
(5.7445)\end{array}$ \\
\hline Lagged Tourism (share of GDP) & $\begin{array}{l}-0.0010 \\
(0.0013)\end{array}$ & $\begin{array}{l}-0.0008 \\
(0.0011)\end{array}$ & $\begin{array}{c}-0.0004 \\
(0.0021)\end{array}$ & $\begin{array}{c}-0.0035^{* *} \\
(0.0014)\end{array}$ & $\begin{array}{c}0.2757^{* * *} \\
(0.0939)\end{array}$ & $\begin{array}{c}0.2522 * * \\
(0.0974)\end{array}$ \\
\hline Lagged Population Density (inhabitants per km2) & $\begin{array}{c}-0.0001^{* * *} \\
(0.0000)\end{array}$ & $\begin{array}{c}-0.0001^{* * *} \\
(0.0000)\end{array}$ & $\begin{array}{l}-0.0000 \\
(0.0000)\end{array}$ & $\begin{array}{l}-0.0000 \\
(0.0000)\end{array}$ & $\begin{array}{c}0.0052^{* * *} \\
(0.0018)\end{array}$ & $\begin{array}{c}0.0048 * * \\
(0.0019)\end{array}$ \\
\hline Lagged Exports (share of GDP) & $\begin{array}{l}-0.0000 \\
(0.0002)\end{array}$ & $\begin{array}{l}-0.0001 \\
(0.0002)\end{array}$ & $\begin{array}{c}0.0004 \\
(0.0004)\end{array}$ & $\begin{array}{c}0.0001 \\
(0.0003)\end{array}$ & $\begin{array}{c}-0.0024 \\
(0.0164)\end{array}$ & $\begin{array}{l}-0.0019 \\
(0.0170)\end{array}$ \\
\hline IHME Mobility Estimates & $\begin{array}{l}0.0023^{*} \\
(0.0013)\end{array}$ & $\begin{array}{c}0.0009 \\
(0.0011)\end{array}$ & $\begin{array}{c}0.0027 \\
(0.0021)\end{array}$ & $\begin{array}{c}0.0022 \\
(0.0014)\end{array}$ & $\begin{array}{c}-0.1748 * \\
(0.0898)\end{array}$ & $\begin{array}{c}-0.1764 * \\
(0.0933)\end{array}$ \\
\hline Cases (per 1000 persons) & $\begin{array}{l}-0.0010 \\
(0.0016)\end{array}$ & $\begin{array}{c}0.0006 \\
(0.0014)\end{array}$ & $\begin{array}{l}-0.0017 \\
(0.0027)\end{array}$ & $\begin{array}{l}-0.0026 \\
(0.0018)\end{array}$ & $\begin{array}{c}0.0861 \\
(0.1204)\end{array}$ & $\begin{array}{c}0.1065 \\
(0.1288)\end{array}$ \\
\hline Constant & $\begin{array}{c}0.0222 \\
(0.0402)\end{array}$ & $\begin{array}{l}-0.0286 \\
(0.0325)\end{array}$ & $\begin{array}{c}0.0262 \\
(0.0679)\end{array}$ & $\begin{array}{c}0.0003 \\
(0.0417)\end{array}$ & $\begin{array}{l}-1.7063 \\
(2.7511)\end{array}$ & $\begin{array}{l}-1.9390 \\
(2.8536)\end{array}$ \\
\hline $\begin{array}{l}\text { Observations } \\
\text { R-squared }\end{array}$ & $\begin{array}{c}32 \\
0.5211 \\
\end{array}$ & $\begin{array}{c}32 \\
0.6721\end{array}$ & $\begin{array}{c}32 \\
0.2498 \\
\end{array}$ & $\begin{array}{c}32 \\
0.5597\end{array}$ & $\begin{array}{c}32 \\
0.6031\end{array}$ & $\begin{array}{c}32 \\
0.5680\end{array}$ \\
\hline $\begin{array}{l}\text { Standard errors in parentheses } \\
* * * p<0.01, * * p<0.05, * p<0.1 \\
\text { The regressions include one-year lag of dependent variables } \\
1 \text { / Average of } Q 1, Q 3, Q 4 \text { in } 2020 \text { minus average of all quart } \\
2 \text { / Average of } Q 1, Q 3, \text { and } Q 4 \text { in } 2020 \text { minus averae of Q1, } C \\
\text { An example of interpretation for columns 1-4: one percenta } \\
\text { by } 20 \text { percent. } \\
\text { An example of interpretation for columns 5-6: one percenta } \\
\text { (column 5) by } 17 \text { percentage points. }\end{array}$ & $\begin{array}{l}\text { ers in } 2019 . \text { Dat } \\
\text { ge point } Q 4 \text { in } 20 \\
\text { ge point one }\end{array}$ & $\begin{array}{l}\text { a is not availab } \\
19 . \\
\text {-year lagged GD } \\
\text {-year lagged GD }\end{array}$ & $\begin{array}{l}\text { e for Q2 } 2020 . \\
\text { P) change in soc } \\
\text { P) change in soc }\end{array}$ & $\begin{array}{l}\text { spending } \\
\text { spending }\end{array}$ & $\begin{array}{l}\text { reases employm } \\
\text { reases labor po }\end{array}$ & $\begin{array}{l}\text { ent (total) } \\
\text { verty }\end{array}$ \\
\hline
\end{tabular}


VIII. FIGURES

Figure 1. Public Social Spending Components in Mexico (Share of GDP)

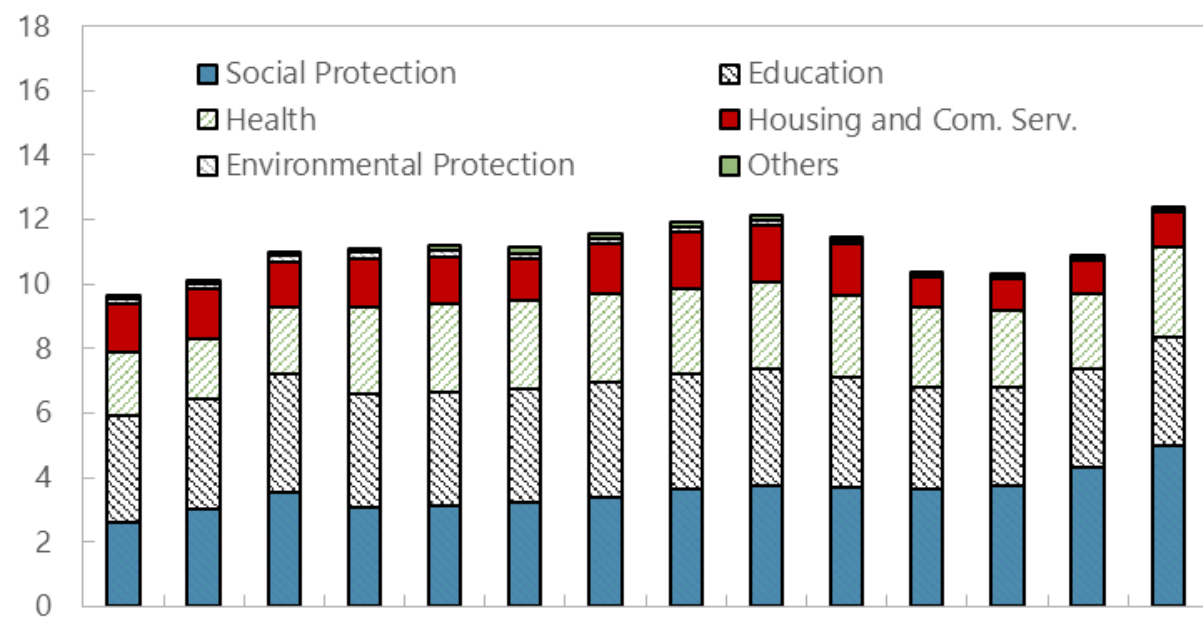

20072008200920102011201220132014201520162017201820192020 Source: Mexico's Ministry of Finance.

Figure 2. Social Assistance Spending in Mexico (Share of GDP)

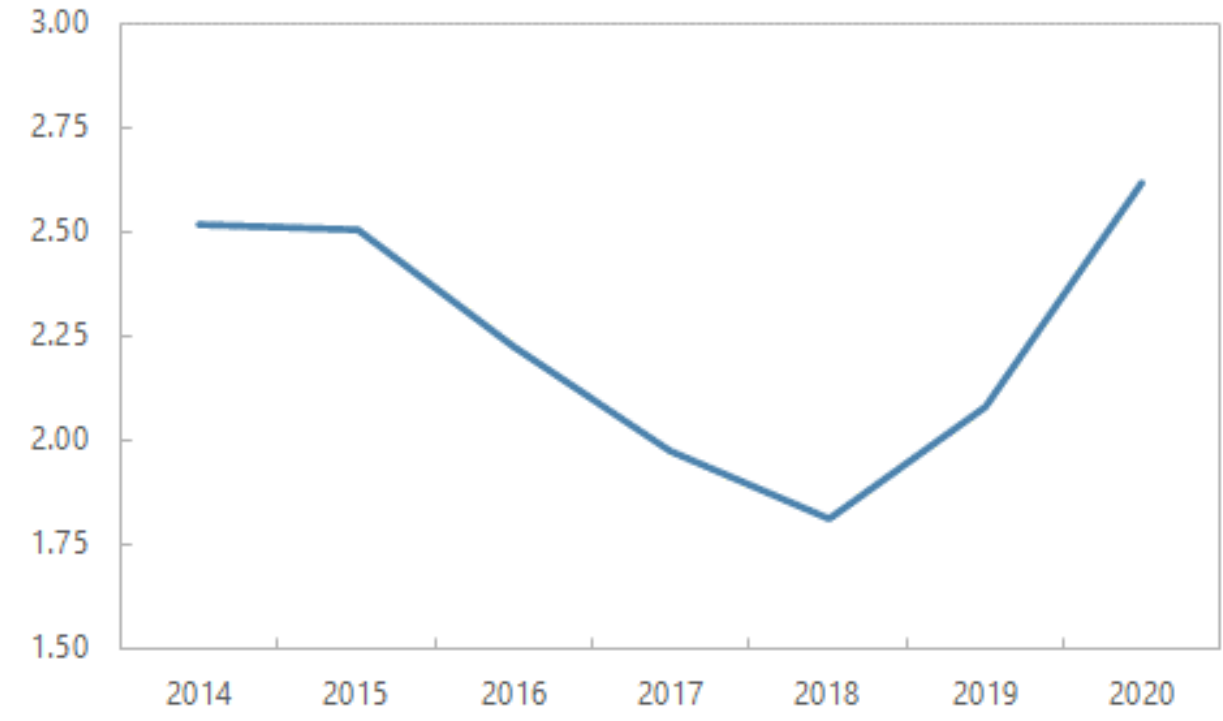

Source: National Authorities. 

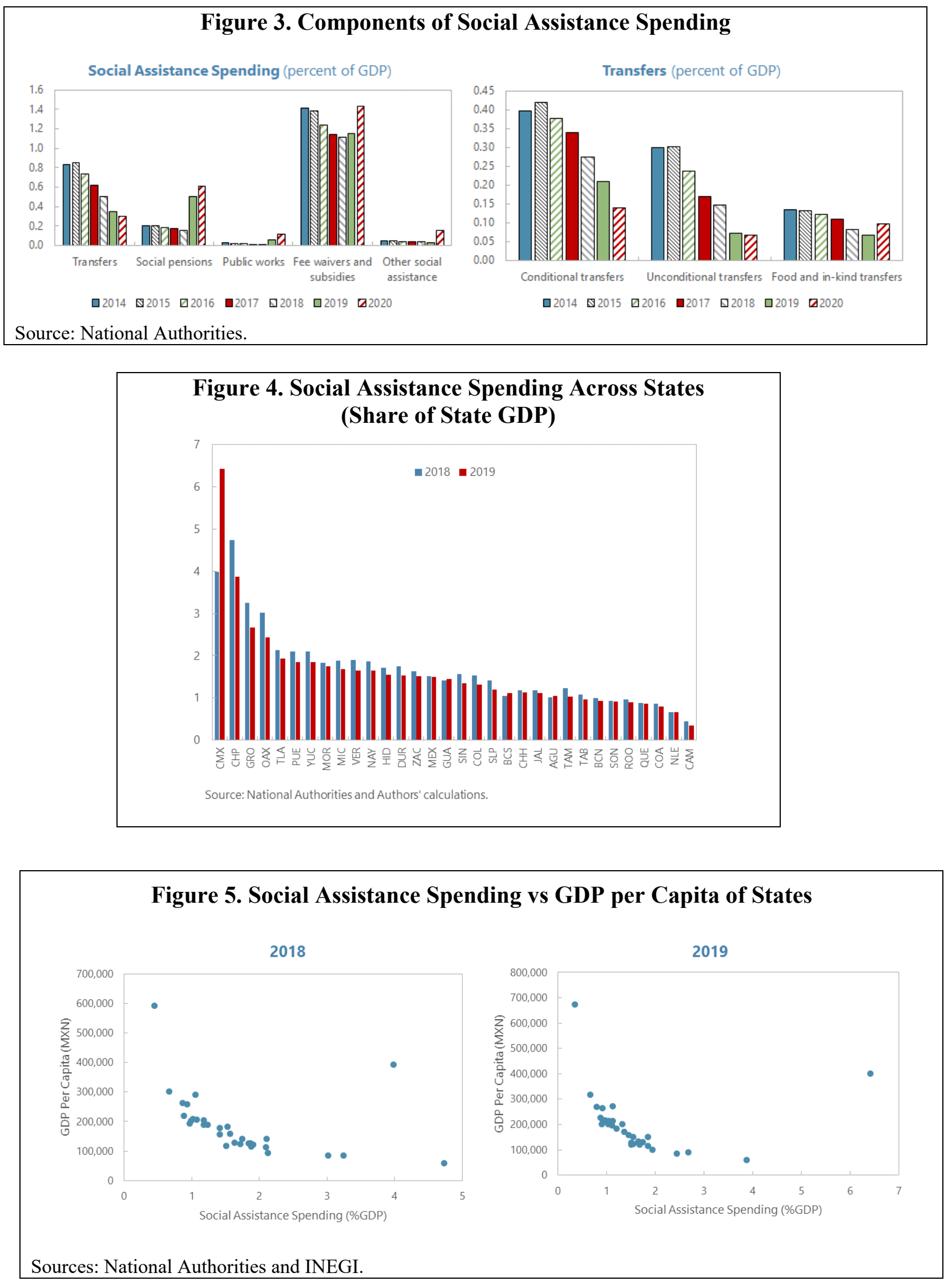

CInternational Monetary Fund. Not for Redistribution 

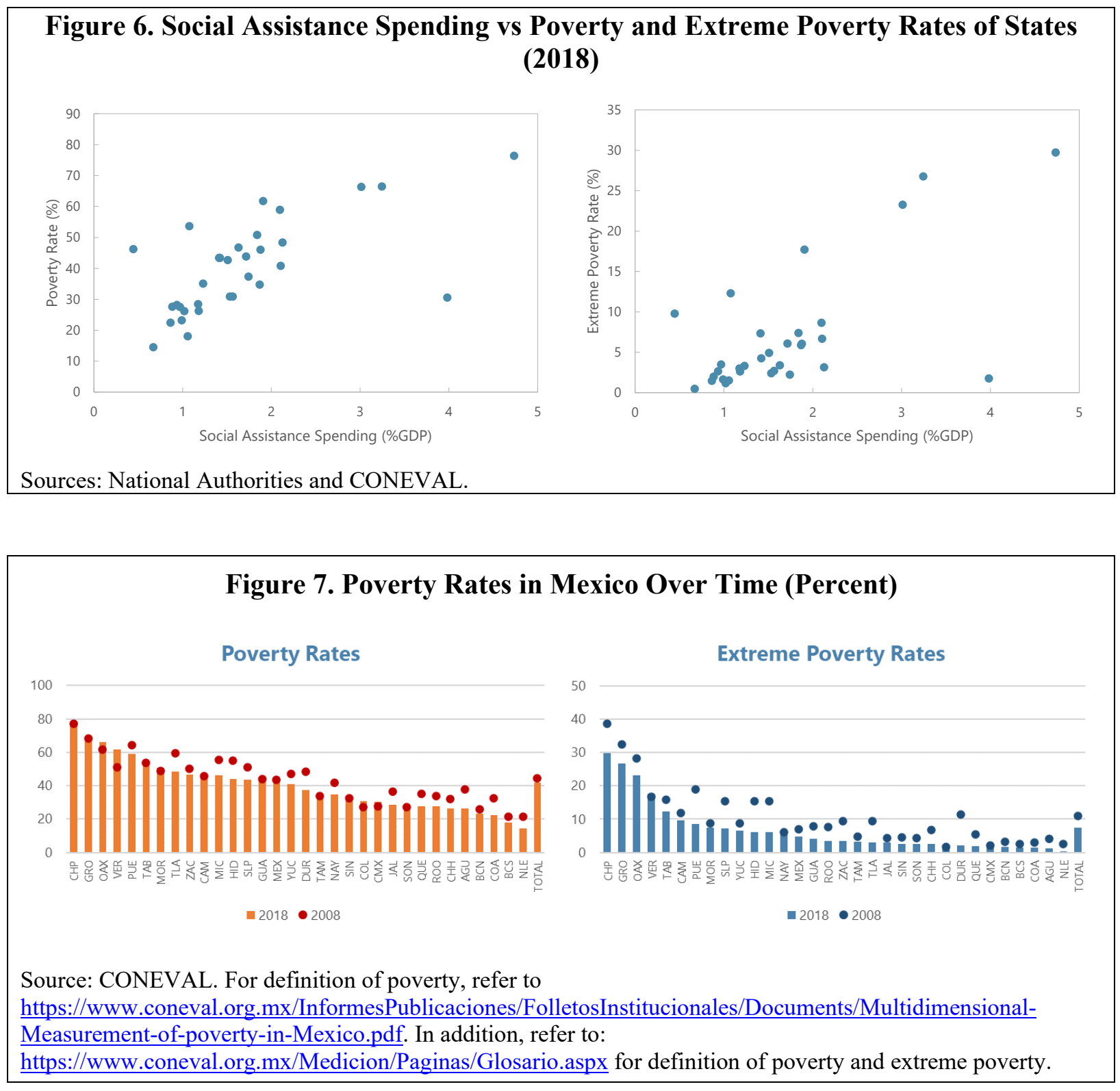


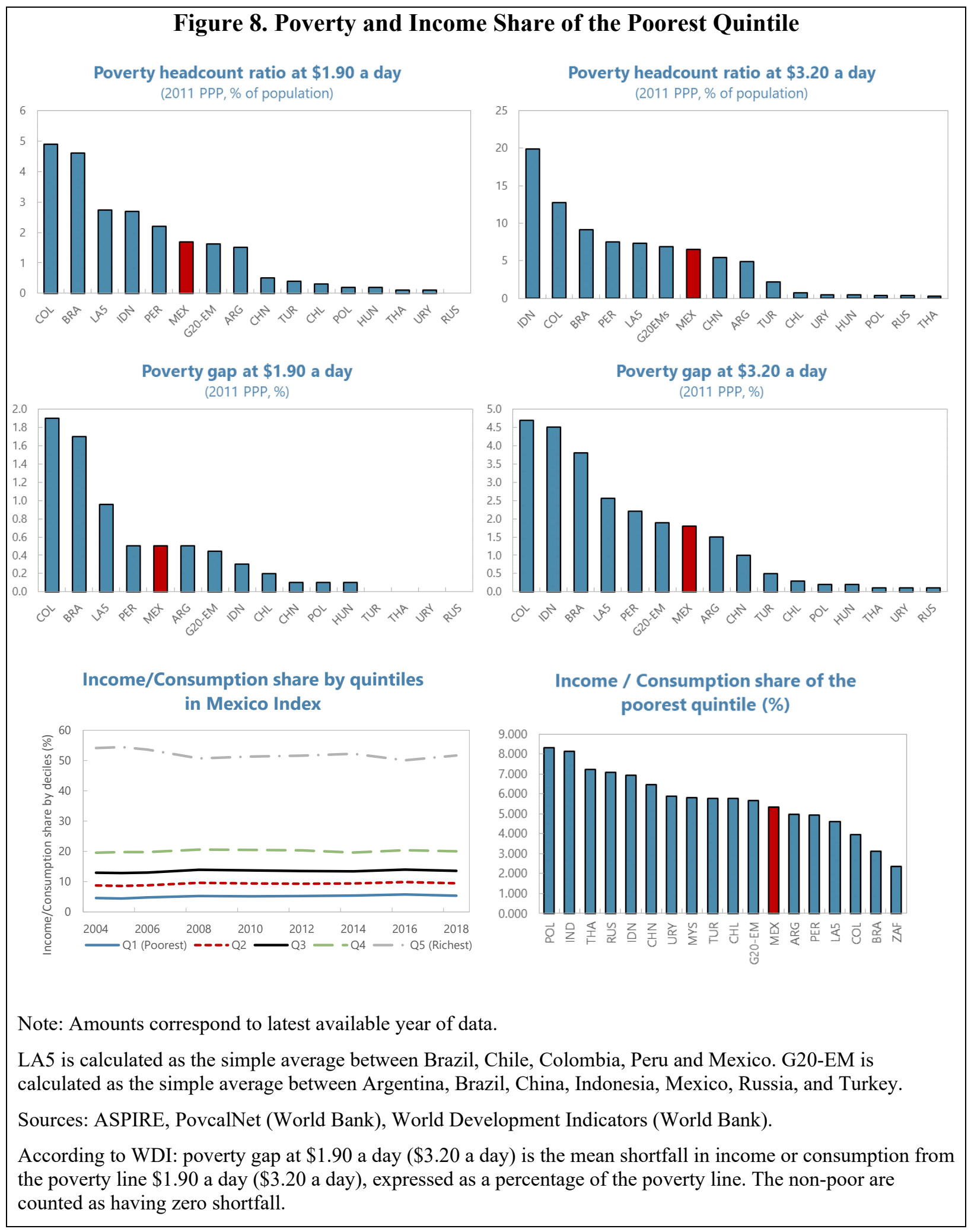


Figure 9. Distribution of Households with Children/Adolescents and with a Head of Household of Working Age, by Access to Social Protection, Around 2018
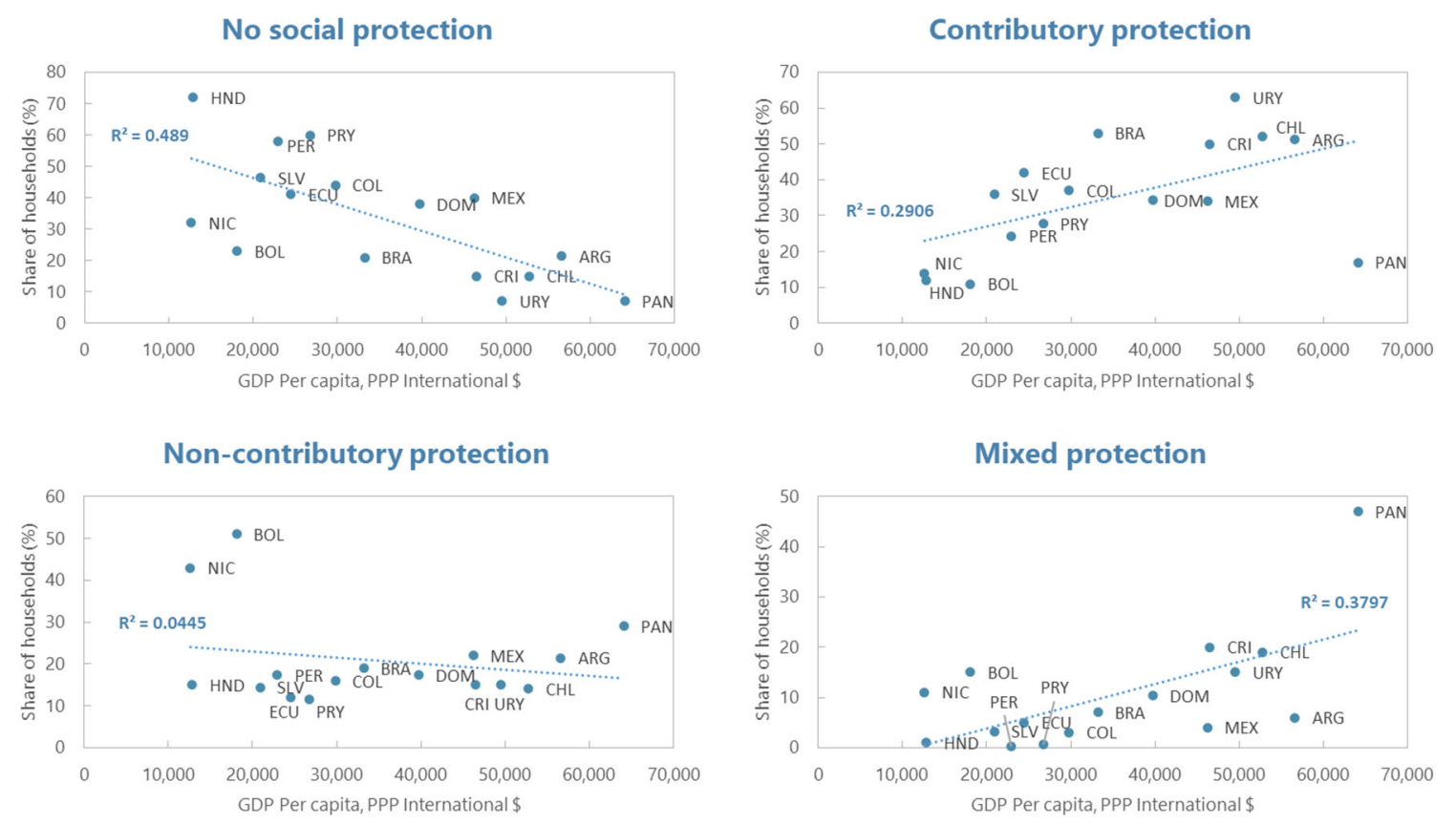

Sources: ECLAC-UNICEF (2020, Figure 2), National Authorities and Authors' calculations. 


\section{Figure 10. Coverage (Percent)}
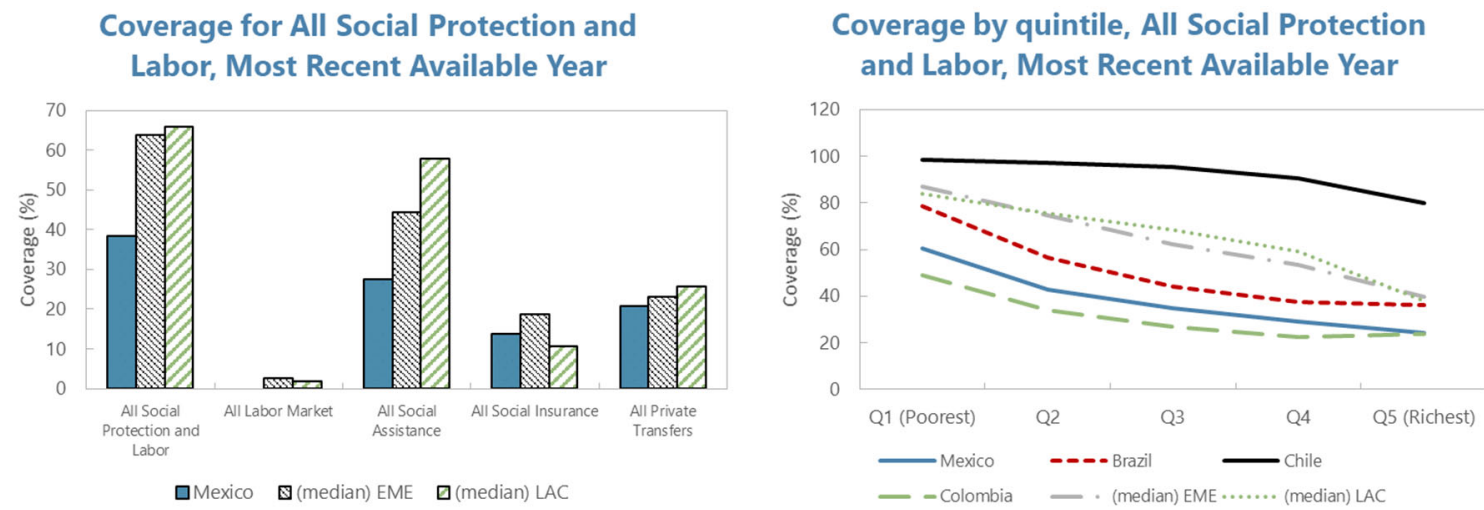

Coverage for All Social Assistance, Most

Recent Available Year

Coverage by quintile, All Social Assistance, Most Recent Available Year
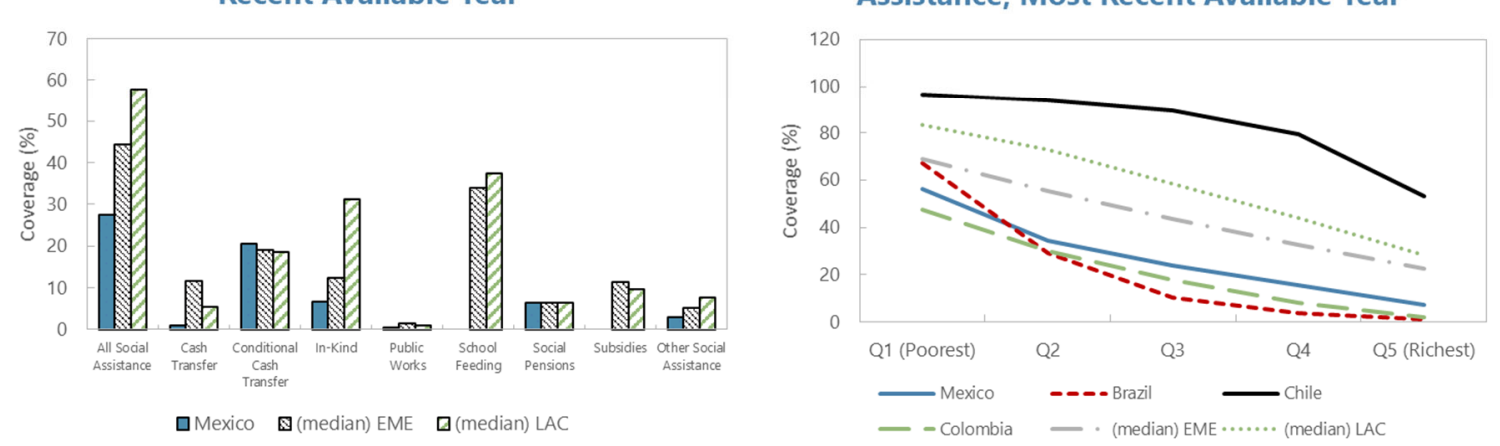

Source: ASPIRE (World Bank).

Note: Coverage is defined as the share of a population or subpopulation (e.g., quintile) that receives a social protection benefit. The calculation is: (number of individuals in the population (quintile) who live in a household where at least one member receives the transfer)/(number of individuals in the population (quintile). 


\section{Figure 11. Adequacy (Percent)}

Adequacy of Benefits for All Social

Protection and Labor, Most Recent Available Year

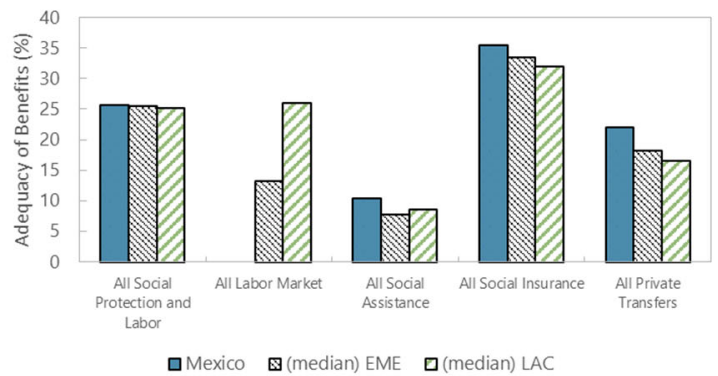

Adequacy of Benefits for All Social Assistance, Most Recent Available Year

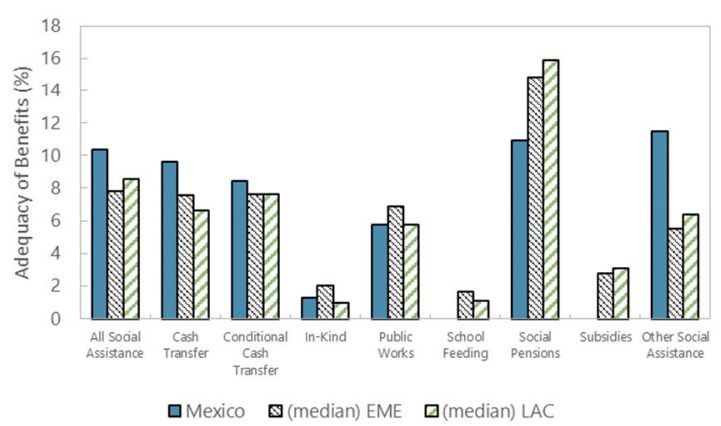

Adequacy of Benefits by quintile, All Social Protection and Labor, Most Recent Available Year

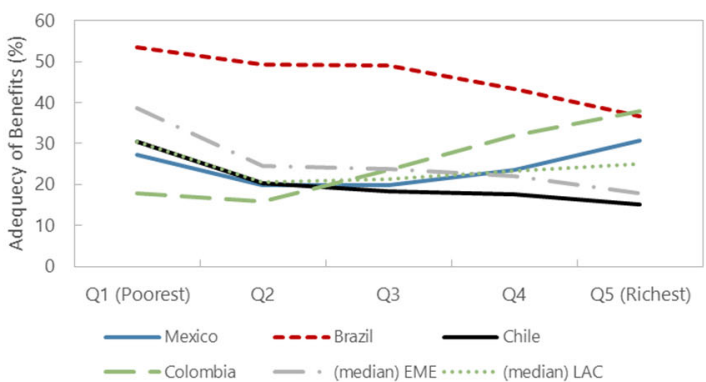

Adequacy of Benefits by quintile, All Social Assistance, Most Recent Available Year

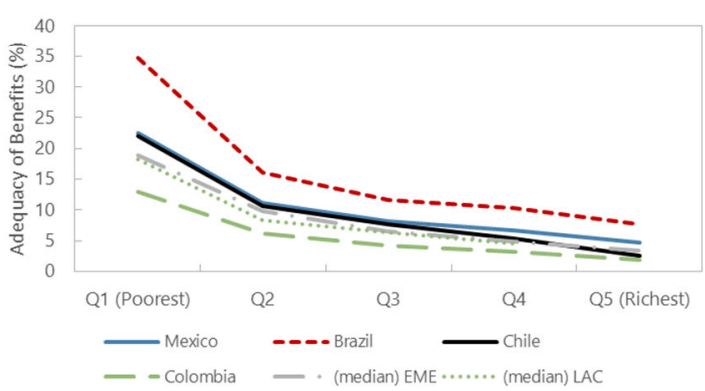

Source: ASPIRE (World Bank).

Note: Adequacy is defined as the total transfer amount received by all beneficiaries in the population (or quintile) as a share of the pre-transfer total income/expenditure of beneficiaries (in that quintile). The calculation is: (Amount of transfers received (by a quintile))/(Total income or expenditure of beneficiaries (in that quintile)). 
Figure 12. Targeting: Benefits (Money) and Beneficiary (People) Incidence (Percent)

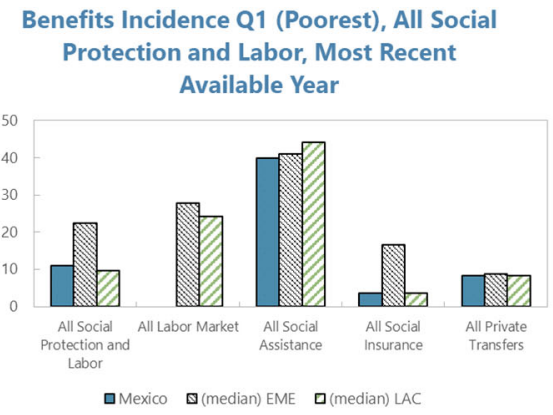

Benefits Incidence Q1 (Poorest) All Social Assistance, Most Recent Available Year

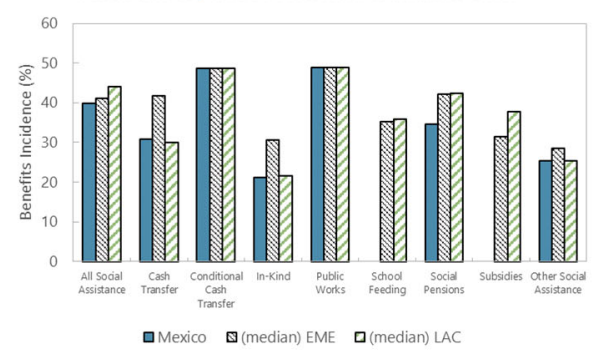

Beneficiary Incidence Q1 (Poorest), All Social Protection and Labor, Most Recent Available Year

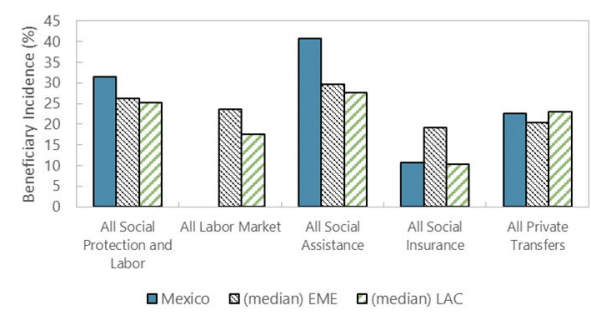

Beneficiary Incidence Q1 (Poorest) All Social Assistance, Most Recent Available Year

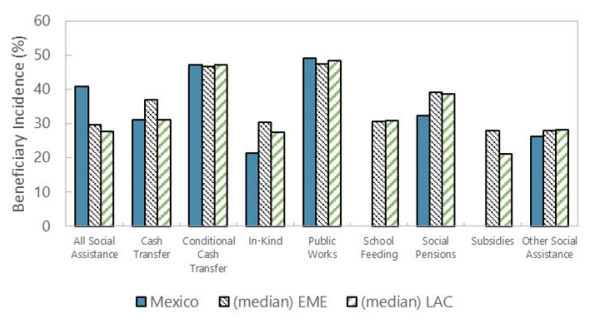

Benefits Incidence by quintile, All Social Protection and Labor, Most Recent Available Year

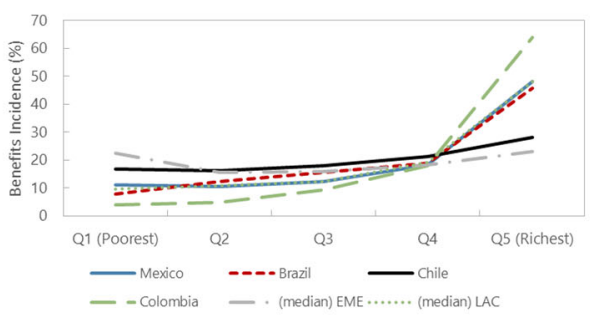

Benefits Incidence by quintile, All Social Assistance, Most Recent Available Year

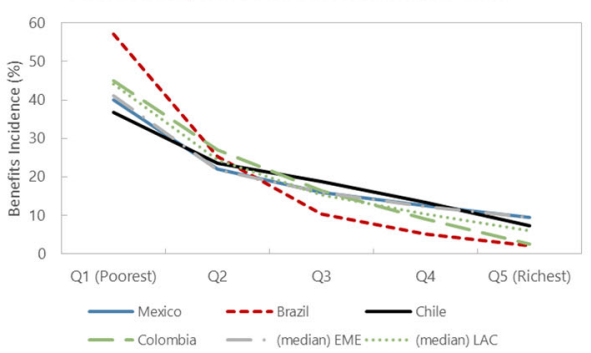

Beneficiary Incidence by quintile, All Social Protection and Labor, Most Recent Available Year

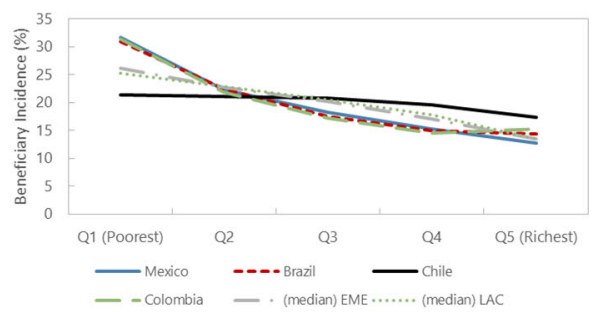

Beneficiary Incidence by quintile, All Social Assistance, Most Recent Available Year

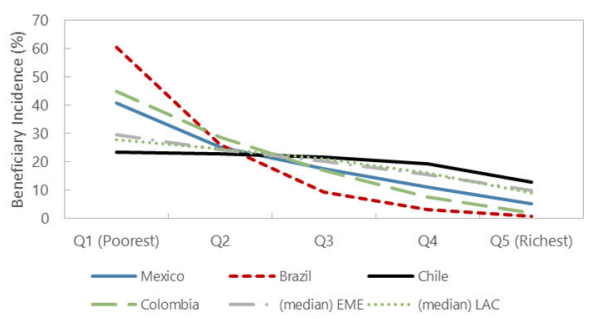

Source: ASPIRE (World Bank).

Note: Benefits incidence is defined as the percentage of benefits going to each group (e.g. quintile) of the pre-transfer welfare distribution relative to the total benefits going to the population. The calculation is: (sum of all transfers received by all individuals in the quintile)/(sum of all transfers received by all individuals in the population).

Beneficiary incidence is defined as the percentage of program beneficiaries in a quintile relative to the total number of beneficiaries in the population. The indicator is estimated by program type and by quintiles of the pre-transfer welfare distribution. The calculation is: (Number of individuals in each quintile who live in a household where at least one member participates in a SPL program)/(Number of individuals participating in SPL programs in the population). 
Figure 13. Non-Contributory Pension Benefits Across Income Groups

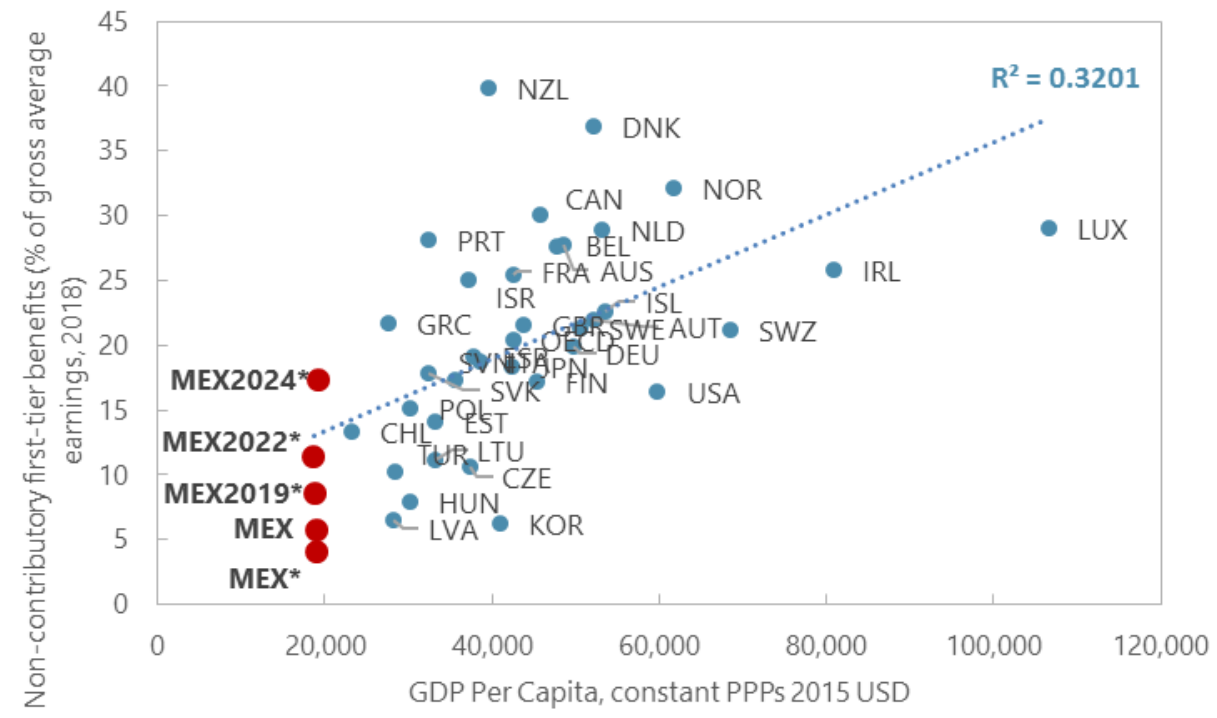

Sources: OECD, WEO, and Authors' calculations. Includes residence-based and targeted noncontributory first-tier benefits. The datapoints marked in asterisks are authors' estimations using government's announced social pension increases. 
Figure 14. Government Education Expenditure, Mexico Versus Other Countries

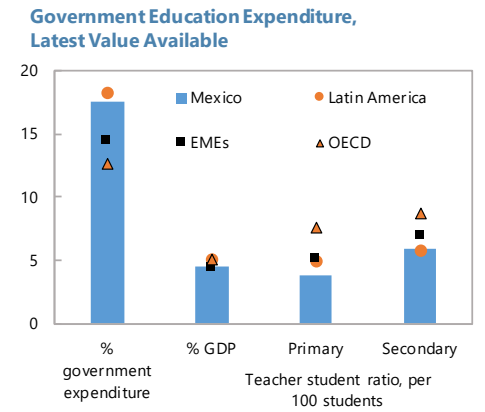

Government Education Expenditure per Student PPP\$ adjusted, Latest Value Available

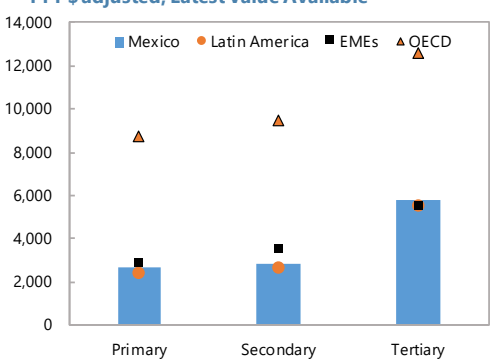

Teachers and Outcome, primary, Latest Value Available 1/

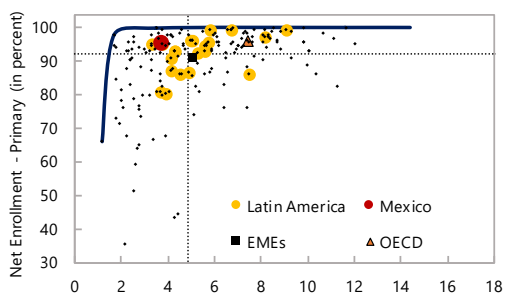

Teacher student ratio, primary, per 100 students

Government Education Spending and Outcome primary, Latest Value Available 1/

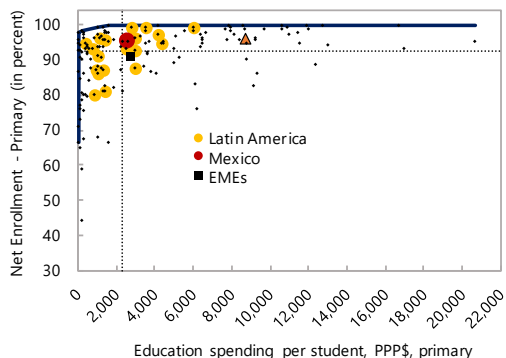

Teachers and Outcome, secondary, Latest Value Available 1/

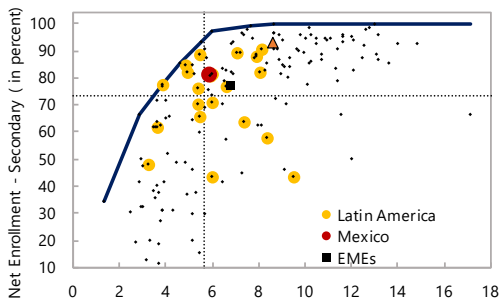

Teacher student ratio, secondary, per 100 students

Government Education Spending and Outcome, secondary, Latest Value Available 1/

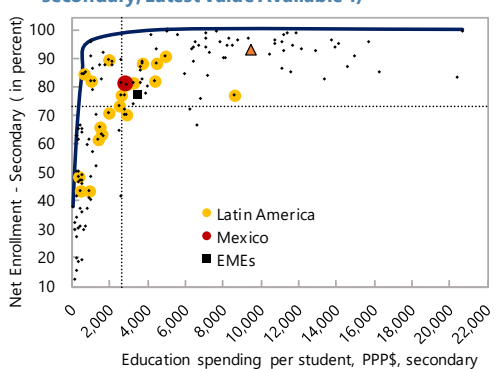

Government Education Spending and Outcome, secondary, Latest Value Available 1/ Available 1/
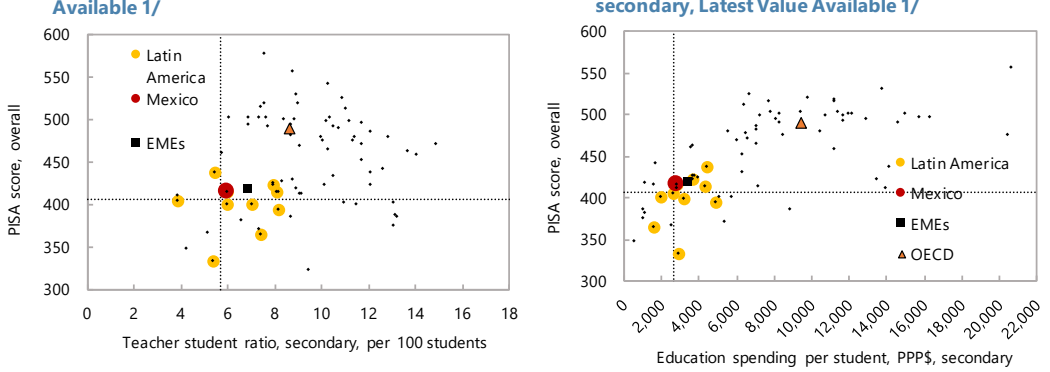

Equcatıon Indıcators, Latest Value Available

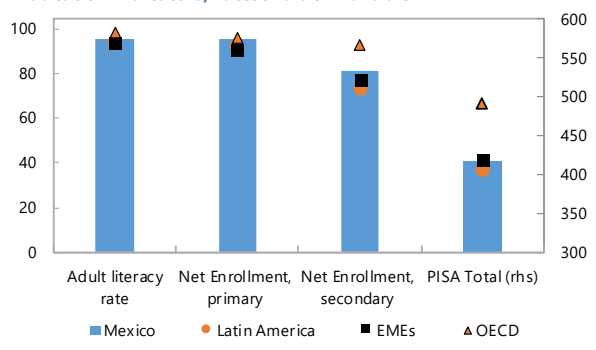

Source: IMF FAD Expenditure Assessment Tool (EAT), World Bank 


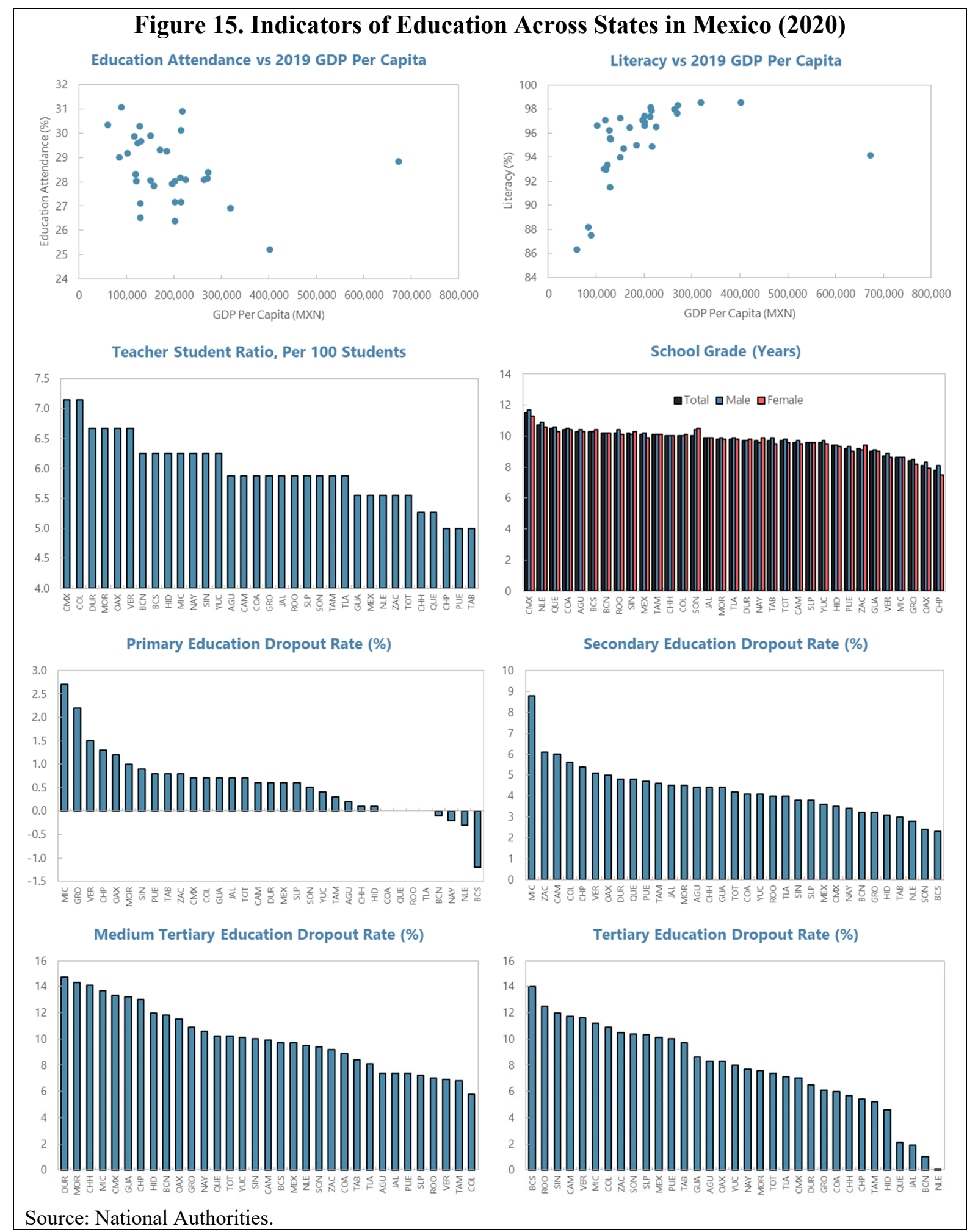


Figure 16. Mexico, Health Expenditure Trend

Health Efficiency Frontier, Latest Value Available (0 - 5,000 PPP\$) 1/

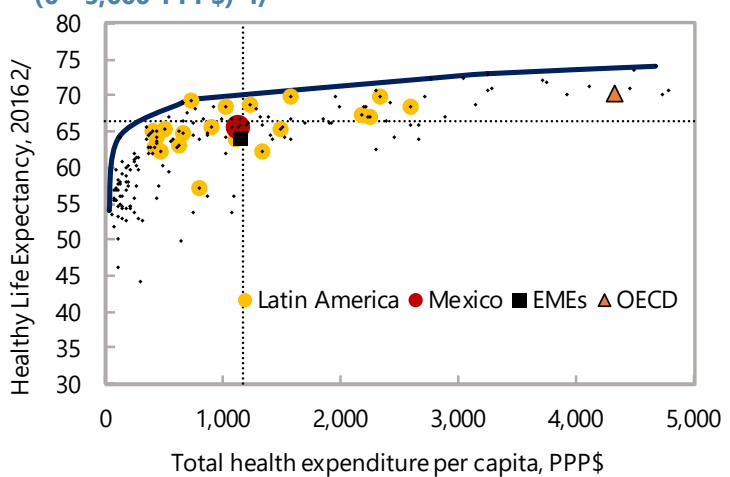

Health Efficiency Frontier, Latest Value Available 1/

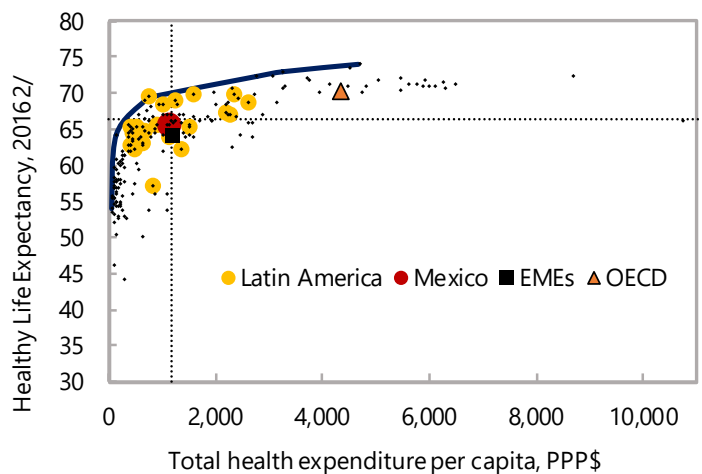

Health Expenditure--Different Metrics, Latest Value Available

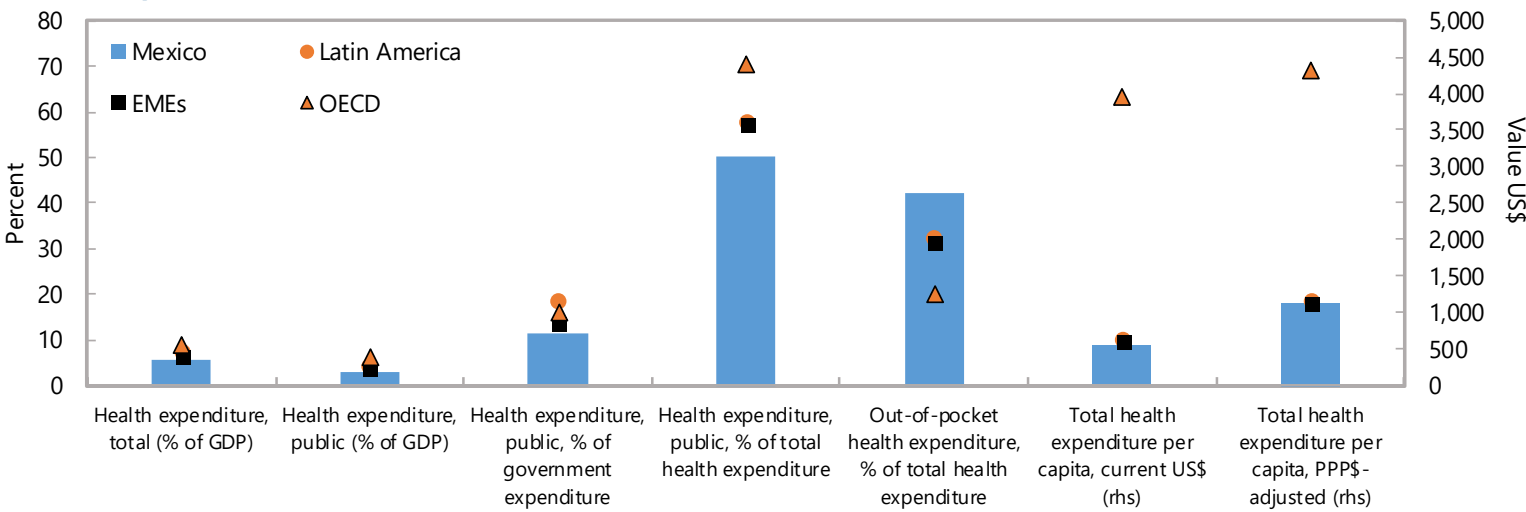

Mexico -- Health Expenditure Trend

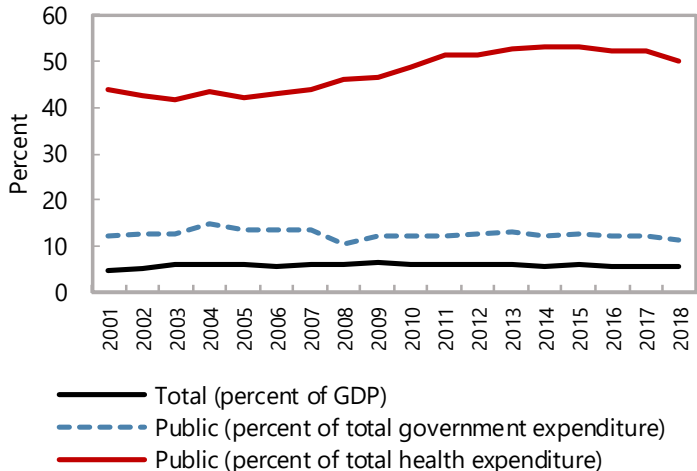

Health Indicators and Health System

Characteristics Indicators, Latest Value Available

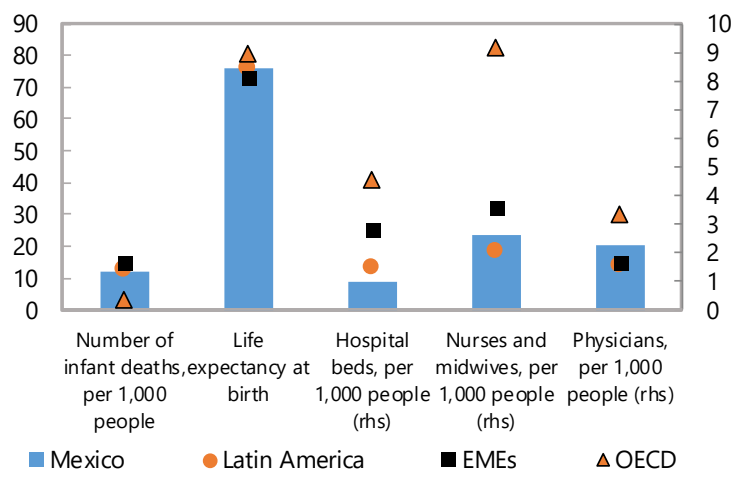

Source: IMF FAD Expenditure Assessment Tool (EAT), World Bank, World Health Organization.

1/ Dashes are the average of Latin America.

2/ Healthy life expectancy (HALE) is a measure of health expectancy that applies disability weights to health states 
Figure 17. Affiliation to Health Services

(Percent of total population in the specified group and state, 2020)
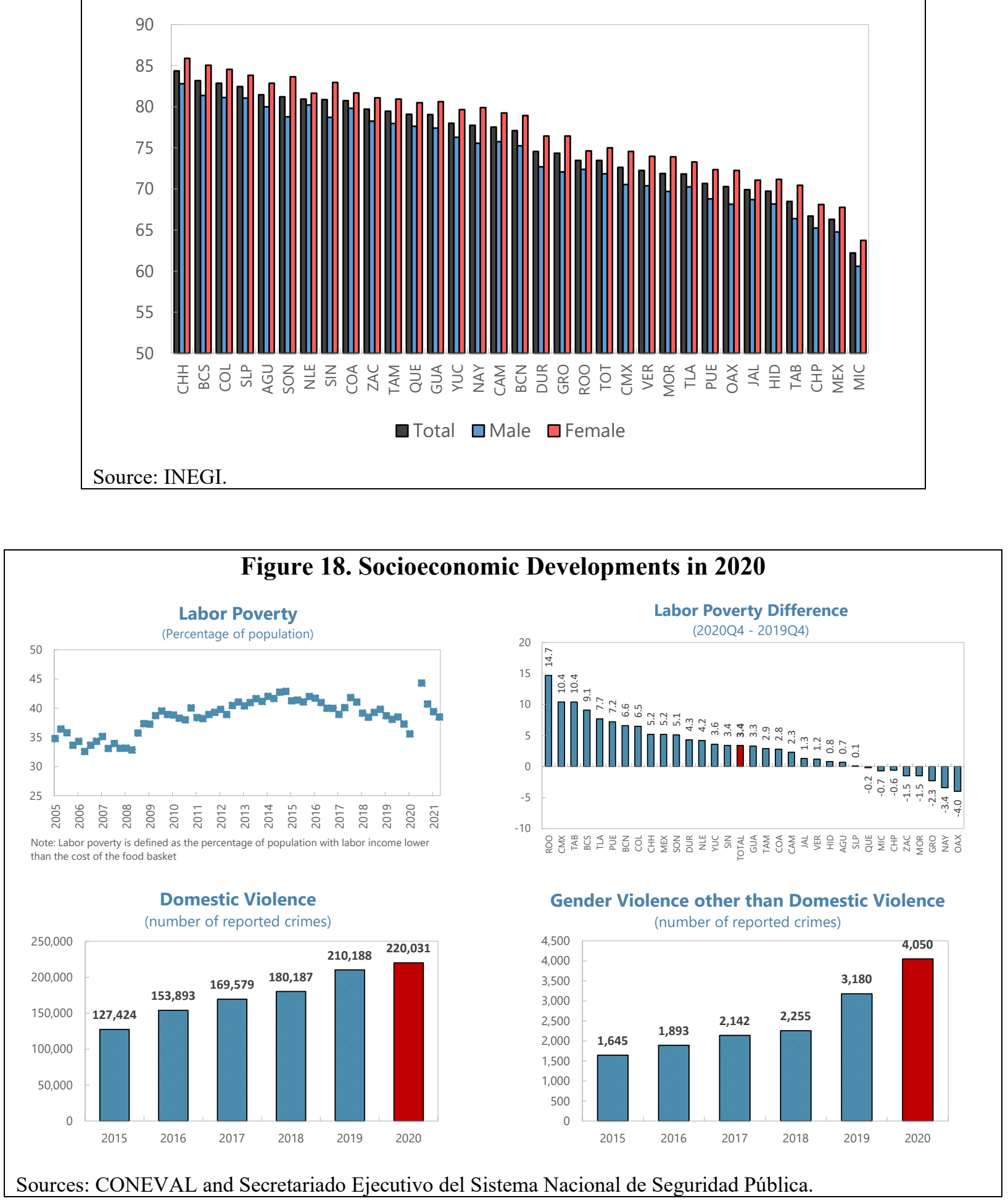
Figure 19. Projected Change in Extreme Poverty Versus Income per Capita (2020 versus 2019*)

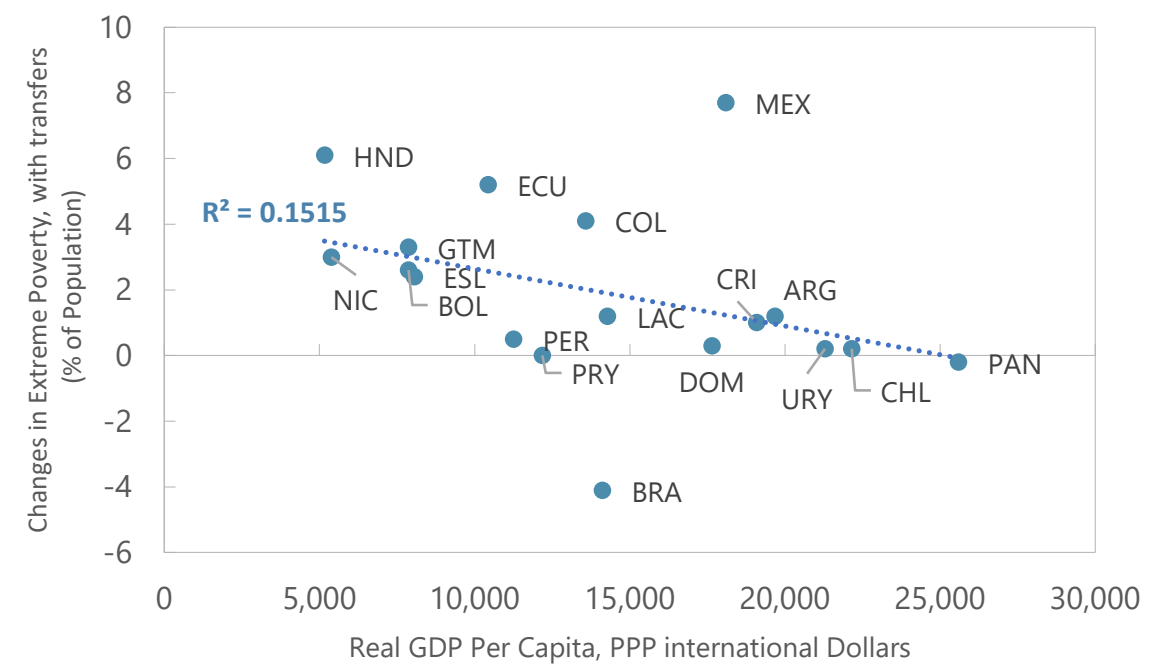

Source: Economic Commission for Latin America and the Caribbean (ECLAC), on the basis of Household Survey Data Bank (BADEHOG), WEO. *Or latest available.

For definition of poverty and extreme poverty, refer to https://repositorio.cepal.org/bitstream/handle/11362/44920/S1900554_en.pdf?sequence=1\&isAllowed=y.

Figure 20. Impact of Change in Social Program Spending in 2020 on Economic Activity and Labor Poverty (Estimates using state-level regression results)

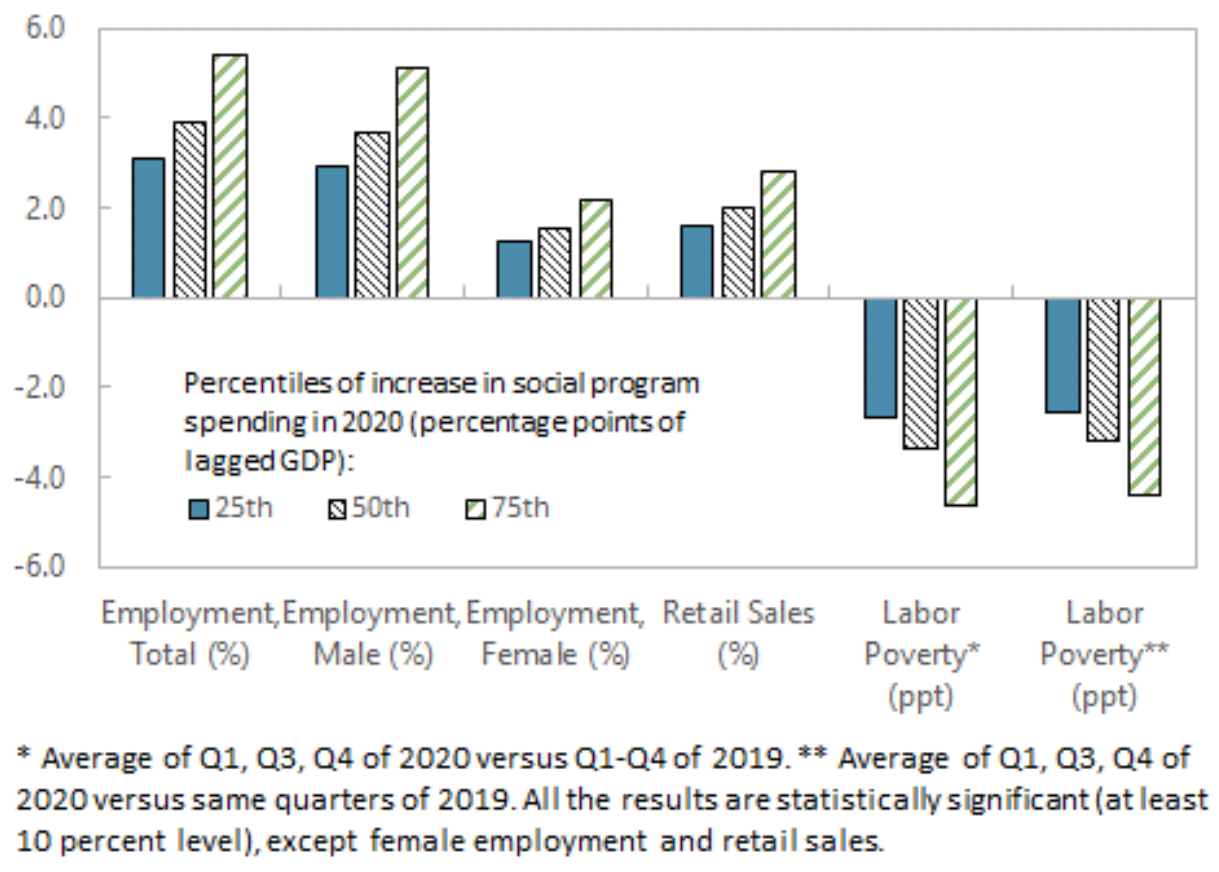

CInternational Monetary Fund. Not for Redistribution 


\section{Figure 21. Internet Access Amongst Students}

15-year-old students with access to Internet at home, by connection type and socioeconomic and cultural quartile, 2018 (Percentages)
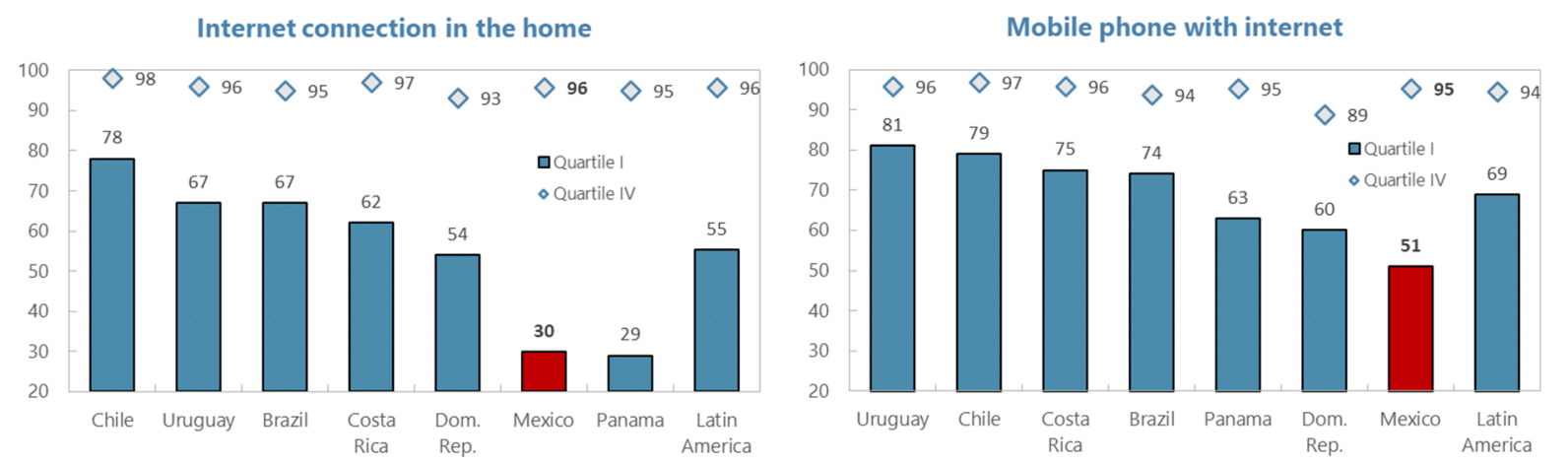

Source: Economic Commission for Latin America and the Caribbean (ECLAC), Social Panorama of Latin America 2020.

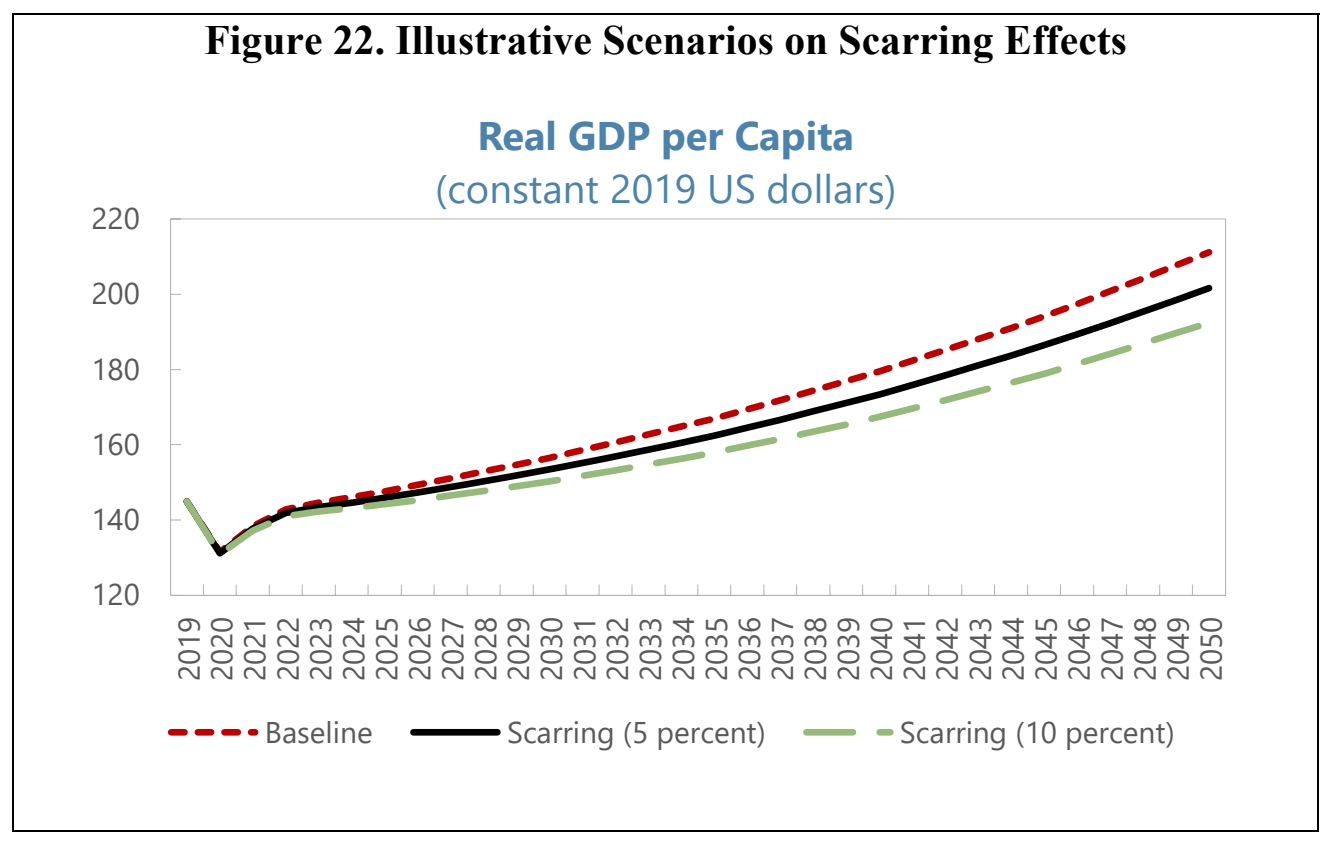

